\title{
A Review of Extremely Fast Charging Stations for Electric Vehicles
}

\author{
Naireeta Deb ${ }^{1} \mathbb{D}$, Rajendra Singh ${ }^{1,2, * \mathbb{D}}$, Richard R. Brooks ${ }^{1}$ and Kevin Bai ${ }^{3}$ \\ 1 Holcombe Department of Electrical and Computer Engineering, Clemson University, \\ Clemson, SC 29631, USA; ndeb@clemson.edu (N.D.); rrb@clemson.edu (R.R.B.) \\ 2 Department of Automotive Engineering, Clemson University, Clemson, SC 29631, USA \\ 3 Min H. Kao Department of Electrical Engineering and Computer Science, University of Tennessee, \\ Knoxville, TN 37996, USA; hbai2@utk.edu \\ * Correspondence: srajend@clemson.edu
}

Citation: Deb, N.; Singh, R.; Brooks, R.R.; Bai, K. A Review of Extremely Fast Charging Stations for Electric Vehicles. Energies 2021, 14, 7566. https://doi.org/10.3390/en 14227566

Academic Editor: Federico Barrero

Received: 13 October 2021

Accepted: 9 November 2021

Published: 12 November 2021

Publisher's Note: MDPI stays neutral with regard to jurisdictional claims in published maps and institutional affiliations.

Copyright: () 2021 by the authors. Licensee MDPI, Basel, Switzerland. This article is an open access article distributed under the terms and conditions of the Creative Commons Attribution (CC BY) license (https:// creativecommons.org/licenses/by/ $4.0 /)$.

\begin{abstract}
The expansion of electric vehicles made the expansion of charging infrastructure rudimentary to keep up with this developing technology that helps people in a myriad of ways. The main drawback in electric vehicle charging, however, is the time consumed to charge a vehicle. The fast charging of electric vehicles solves this problem thus making it a lucrative technology for consumers. However, the fast charging technology is not without its limitations. In this paper we have identified the technology gaps in EV fast charging stations mostly focused on the extremely fast charging topology. It will help pave a path for researchers to direct their effort in a consolidated manner to contribute to the fast charging infrastructure. A thorough review of all aspects and limitations of existing extremely fast charging (XFC) stations have been identified and supporting data are provided. The importance of DC power network based on free fuel energy sources and silicon carbide-based power electronics are proposed to provide ultra-low cost and ultra-high speed XFC stations.
\end{abstract}

Keywords: electric vehicles; extremely fast chargers; power electronics

\section{Introduction}

Worldwide awareness on climate related challenges and sustainable mobility, motivated to control the emissions from the gasoline-powered internal combustion engine vehicles (ICEVs), which constitutes to $16.2 \%$ of the total emission worldwide [1]. Apart from ground transportation via passenger cars, the heavy-duty commercial vehicles constitute a major number of electric vehicles in usage today. Lightweight Battery electric vehicles represent only $2.5 \%$ of total vehicle sales [2]. The same can be said for the aviation and marine industry where they have the potential to be electric or, as in the case of ships, are already electric but use fossil fuels to generate power on-board. Replacing these vehicles with battery vehicles for all three modes of transportation can bring a sharp reduction in carbon emissions. Several applications in aviation and ground transportation have been advancing at a remarkable pace due to the progress of electric motors, power electronics, and batteries etc. This has contributed to the commercial take-off of fully electric transportation. According UBS estimation, the aviation industry will be $25 \%$ hybrid or fully electric by 2035 [3]. It is also hard to standardize safety measures and requirements in air and maritime transportation due to regulations and cross border operation. Therefore, it might be safely concluded that battery electric vehicles (BEV) are making ground transportation the pioneer of electrification of transportation [3]. To implement this, the following are the key requirements: (i) the upfront cost and cost of ownership of electric vehicle must be equal to or less than ICEVs, (ii) the range of electric vehicles (EVs) must be equal or greater than ICEVs, and (iii) green energy must be used to create extremely fast and low-cost charging infrastructure. Industry is making great progress to address the first two points. As an example, Tesla is planning to introduce 25,000 EVs USD [4]. Although the industry 
is doing their best work to provide low upfront cost and high range, the implementation of green and sustainable energy is yet to be seen on a large scale. Therefore, the objective of this paper is to review the key challenges that have the potential to implement sustainable green energy as the source of electric power and silicon carbide power electronics for wide range implementation of electric vehicles at large scale. There are currently four levels of charging in industrial usage. The IEC 61851 describes the first three levels are AC charging ranging from $250 \mathrm{~V}(1 \mathrm{P}), 250 \mathrm{~V}(1 / 3 \mathrm{P})-480 \mathrm{~V}(1 \mathrm{P})$ and $480 \mathrm{~V}(3 \mathrm{P})$ respectively [5]. Clearly, none of these satisfy the need for extreme fast charging needed for heavy duty vehicles. $250 \mathrm{~V}$ and $32 \mathrm{~A}$ will produce $8 \mathrm{~kW}$ whereas the thermal equivalent of one gallon of gasoline is $35 \mathrm{kWh}$ [6]. According to EPA (Environmental Protection Agency) guidelines $35 \mathrm{kWh}$ must drive at least 99 miles. Therefore, transferring a similar amount of energy in terms of an EV will require $4.5 \mathrm{~h}$ of charging for a mid-range sedan like Nissan Leaf which is impractical [7]. As level 1 and level 2 charging is widely implemented, we have reviewed the DC fast charging and pointed out the fundamental changes required to accelerate the electrification of surface transportation. Recently, Tu et al. (2019) have published a review article [8], however the article had limited coverage that mostly focused on the several power electronics architectures and not much on the other aspects like review of cyber security measures and protection design. That provide the pathways to low-cost XFCs. The authors of reference [8] don't delve into the subject of DC grid or silicon carbide power electronics for fast charging. In reference [9], emphasis is placed on the charging equipment and inductive charging. The scopes of inductive charging remain doubtful economically for heavy duty vehicles because of their high losses. Similarly, in reference [10] all levels of charges are reviewed, but less emphasis is given on fast charging as the need of the hour. Another review paper focuses solely on the charging standards while the technical aspects are barely mentioned [11]. The focus of reference [12] is on DC fast charging but only on energy storage design and not power electronics. The emphasis of this review paper is on relevant power electronics technologies of DC fast charging and other aspects such as cyber security, protection, and impact of DC power green sustainable electrical power networks and the role of silicon carbide power electronics in fast deployment of XFC on a large-scale basis. The main problems addressed will be the high losses occurred during power electronics conversion, the poor state of DC protection, and the gaps in cyber security measure. In this article we have provided a potential solution to all the questions by researching existing resources and proposing the best-case scenario results. The novelty of research lies in the comprehensive solution provided in every aspect of charging station which is not found in current literature as mentioned above.

The rest of the paper is as follows; Section 2 contains the background information that motivated this research. Section 3 shows the infrastructure requirement for XFC charging station deployment on a large scale. Section 4 discusses the impact of charging station on grid stability, Section 5 covers an overview of charger connector. Section 6 explains the different power electronics topologies in EV stations keeping in mind that the station is supposed to charge several vehicles at the same time. Section 7 analyses the cost of an XFC station. Section 8 tries to explore the sustainability impact of an XFC EV station. Sections 9 and 10 show the protection system and reliability analysis of Electric Vehicle Charging Station (EVCS). Section 11 shows the cyber threats imminent upon a fastcharging station. Section 12 sheds lights on the adaptation of silicon carbide to improve the performance of power electronics in XFC. In Section 13, we have discussed the maintenance of DC fast charging stations. Section 14 discusses the possibility of XFC in near future and the concluding remarks are stated in Section 15.

\section{Background Information}

Label conventions define that equipment which is continuously operating above $150 \mathrm{kWW}$ are considered extremely fast charging (XFC) [8]. In general DC fast charging may be harmful to the EV battery due to thermal issues. Repeatedly heating the battery from DC fast charging is thought to accelerate battery degradation over time. To mitigate 
this, some EV manufacturers have suggested that EV owners refrain from using DC fast charging every day. The new On-Route Battery warmup introduced by Tesla prepares the battery pack thermally by automatic software before arriving at a Supercharger station. The navigation system detects the driver's commands to be redirected to the Supercharger station and the thermal preparation gives peak charge rate faster and longer while parked at the station [13]. A complete consideration of industry standards, grid impacts, and other technical policy issues need to done before implementing such a complex EV charging infrastructure.

The block diagram of DC extremely fast charger is shown in Figure 1 [14] which is connected to the grid. Since our existing electricity infrastructure is based on AC, components shown in blue color within red square are required to convert $\mathrm{AC}$ input of the grid to DC input power of XFC. These components are not required for DC grid with the net result of cost reduction of XFC and a higher system reliability (due to less number components in the system). Thus, an important aspect of background motivation lays in the end-to-end DC

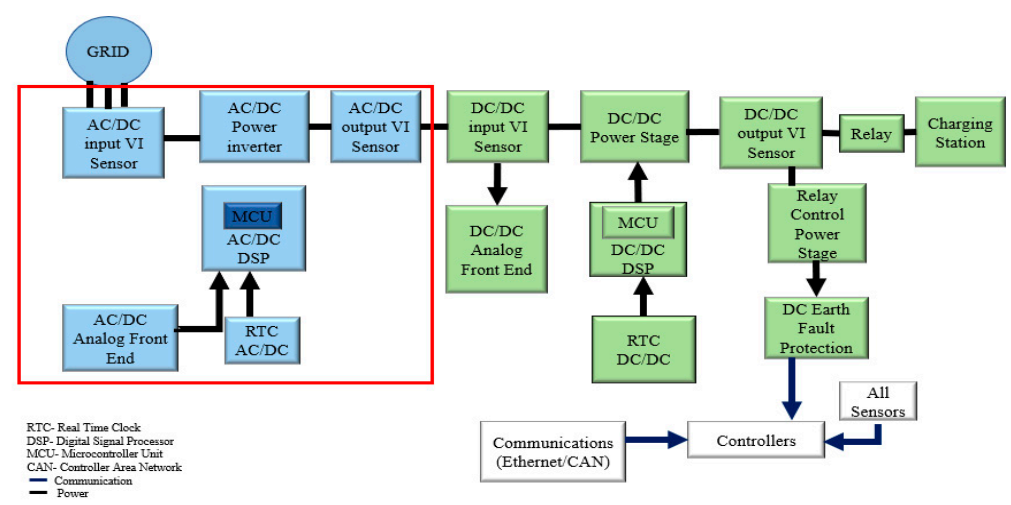

Figure 1. Block diagram of DC XFC Charger connected to the grid [14].

Infrastructure as shown in Figure 2 [15]. The transmission losses caused by AC-DCAC conversion can simply be averted by adopting a fully DC system. But the current XFC infrastructure being AC, lacking this opportunity. More on this has been explained in the discussion in Section 13.

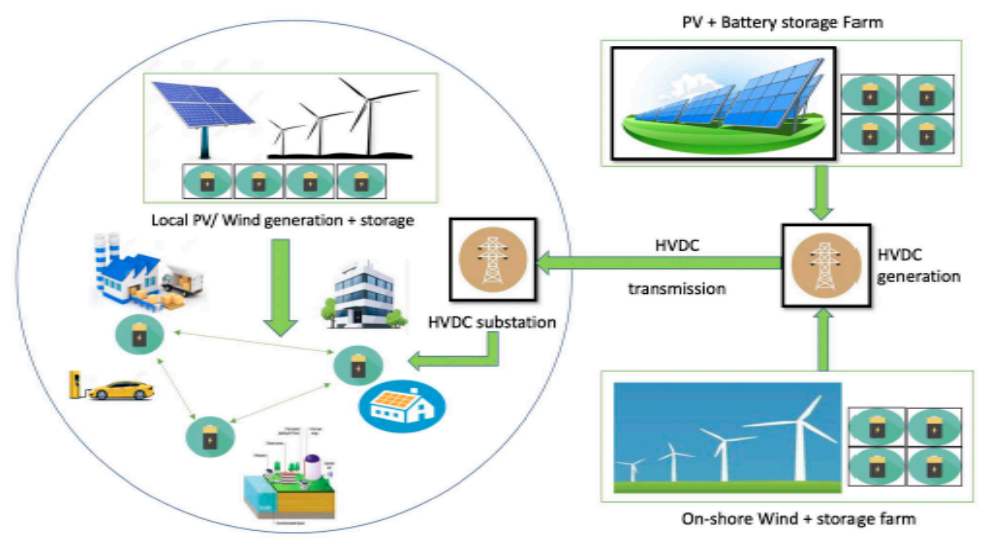

Figure 2. 100\% DC Grid Powered by PV, and or Wind and Battery [15].

The heavy-duty charging cable has additional maintenance issues as they are made of bulky liquid cooled assemblies. The MW level charging cable must be in between 1000 to $1500 \mathrm{~V}$ and 1000 to $3000 \mathrm{~A}$. The safety issue in MW level is more important than level one and level 2 charger to protect equipment and personnel [16]. A new kind of fault due to the high voltage present on wye capacitor filters occur in this level as well. The lack of clear guideline based high voltage level charging, makes the job of infrastructure harder. In case of renewable integration of MW level charging, their sources like PV or 
wind must be coupled to a common DC bus. Hence, research is also necessary on the mechanical side to identify how many parallel modules can be connected on each energy node. In case of the DC-to-DC converters they will need additional charging intelligent controllers to coordinate the usage of charging nodes for multiple vehicles relying on the same charging power.

The summary of currently available chargers is given in Table 1 . It is evident that there is an urgent need of extremely fast chargers (XFCs).

Table 1. Types of Fast Charger available as of Now [8].

\begin{tabular}{cccc}
\hline $\begin{array}{c}\text { Type of Fastest Charger } \\
\text { Available in Market }\end{array}$ & Power (kW) & Efficiency & $\begin{array}{c}\text { Time to Add } \\
\text { 200 Miles }\end{array}$ \\
\hline PHIHONG Integrated type & 120 & $93.5 \%$ & $30 \mathrm{~min}$ \\
Tesla Supercharger & 135 & $91 \%$ & $27 \mathrm{~min}$ \\
EVTC espresso and charge & 150 & $93 \%$ & $24 \mathrm{~min}$ \\
ABB terra HP & 350 & $95 \%$ & $10 \mathrm{~min}$ \\
\hline
\end{tabular}

Several problems cloud the possibility of a widespread XFC charging station network. The heavy load on the grid during fast charging hours remain one of the biggest concerns. Designing the correct algorithm as mentioned in reference [17] is the biggest engineering problem that remains to be addressed in the fast-charging scenario. In retrospect, the authors of reference [15] propose a battery and photovoltaic based charging network for this specific purpose so that the charging infrastructure remains completely separated from the AC grid and the load is minimized. The scope of this paper is to point out the advantages of DC charging and the dependence on solar and or wind as energy sources with batteries incorporated is a new perspective to minimize the stress on an already overloaded grid.

\section{XFC Charging Station Infrastructure}

The sustainable option of EV is ignored by the masses due to the time of replenishing the fuel (Electricity) in them. Consumers are accustomed to the idea of visiting the gas station, refueling their cars in $5 \mathrm{~min}$, and getting back on the road. Once fueled, a typical Internal Combustion Engine Vehicle (ICEV) runs 300 to 400 miles making that technology lucrative. Thus, the sole focus of EV charging station placement and planning research must be on making the charging stations more like gas stations. The existing fast charging architecture needs service transformers to be connected to the Medium Voltage (MV) line, that adds up to the size, cost and has a complicated installation process thus increasing labor cost as well [18]. More light on cost analysis of XFC is shed on Section 7.

The prevalent EV charging technology are level 1 and level 2 which can be found at home or workplaces. An average American travels approximately 30 miles per day, spending about $46 \mathrm{~min}$ in commute $[19,20]$. Therefore, the level 1 and level 2 charging are serving adequately for their day-to-day need. However, the long-distance trips in EVs still remain a challenge. Unplanned trips or days where there might be a sudden blackout or power outage also need to be considered for the EV to go uncharged a few days. To eliminate this problem XFC is an essential technology. Other than serving in the earlier scenarios, XFC can be a boon in multiunit dwellings in metropolitan environments, the long-distance commercial transport as buses, trucks or other shared fleets will also benefit from XFC as those vehicles are bigger and need more kWh of power and more time to charge from level 1 or 2 charging thus making their charging prolonged at present [20].

\section{Grid Stability}

The heavy load imposed on power grid during charging is a big challenge yet to be addressed. Recent XFC technologies are capable of even drawing $350 \mathrm{~kW}$ for one single car [6]. When the heavy-duty vehicles with 1.2 MW battery pack are commercialized the fast-charging voltage level will go even higher causing a negative impact on the grid. 
Although the growth of EVs and their associated charging stations has a positive impact on the environment and related economic growth, it can have detrimental effects on the power grid [21]. These effects need to be understood before moving to possible remedies or ways to mitigate them. Increased peak demand, reduced reserve margins, voltage instability and reliability problems are some of the challenges associated with High charging load derived from fast charging.

The probable solutions to these problems are analyzed below.

\subsection{Smart Charging}

Smart charging intelligently manages the EV charging without destabilizing or overloading the grid. It enables opening pathways by the utility companies and charging operators to communicate with each other. Depending on the load on the grid these smart chargers will increase or decrease the power supplied to the charging stations [21]. A network operator will have the ability to regulate the flow of power to the stations depending on the load on the grid. This enables features like power sharing, power boost and dynamic power sharing. Although a promising solution but the drawback of human error is the main concern.

\subsection{Vehicle to Grid (V2G)}

With renewable integration, the $\mathrm{V} 2 \mathrm{G}$ algorithm is a useful strategy to maintain grid stability. The operating principle is akin to smart charging but here the grid is the master and charging station is the slave in this two-point operation. It also enhances the grid's ability to self-balance. This is imperative when renewable resources are integrated in the AC grid [21]. Without V2G long distance transmission costs will increase as energy from farther reserves will be needed to transport power thus raising the tariff. The critical drawback of this system is the availability of reserved power at a certain location and the associated transmission cost. A minutely detailed algorithm operating accurately is imperative for the success of V2G operation. For Level 1 and Level 2, V2G is already showing promising results. However, their effectiveness in XFC is yet to be analyzed on a large-scale system. To stabilize grid, separating it from charging network remains the most efficient solution.

\subsection{A Microgrid Ecosystem}

The correct amalgamation of microgrids instead of a large power network is good solution to the problem of grid stability. Defined by power utilities, "A microgrid ecosystem is a locally interconnected system with clearly defined electrical boundaries" [21]. It has several advantages as follows:

- Integrates loads and distributed energy resources, including BESS.

- Compound power generating resources.

- Both grid-connected and be off grid.

- A single unit with its own autonomous control in both approaches.

- Several kilowatts to multiple megawatts with a voltage range up to megavolts can be the power range.

Globally, utility companies are welcoming charging infrastructure, because it is a revenue generating business model with long-term turnover. However, haphazard installation of charging stations to fulfill ever growing demand might destabilize the grid. Therefore, it's imperative that the utility companies develop a comprehensive Electrical Service Requirement (ESR) documentation for the charging companies stipulating the boundaries. In conclusion, the energy management and grid stability are a growing research area and authors here have aimed to summarize the efforts for a comprehensive review article.

\section{Charger Connector Review}

The charge reception of the batteries and the ratings of the charger are not only the limiting factors for power delivered to EVs but it is also dependent on the type of connectors 
as well as shown in Table 2 [22,23]. According to the power output and charging speeds available to EVs the charger connectors are divided into three types slow, fast, and rapid.

Table 2. The types of XFC charger available in the market [22,23].

\begin{tabular}{llllll}
\hline Shape of Inlet & CHAdeMO & CCS Combo 2 & GB/T 2D234 DC & $\begin{array}{l}\text { Tesla Super } \\
\text { Charger }\end{array}$ \\
\hline Manufacturer & CCS Combo 1 & CHW & $1000 \mathrm{~V} / 200 \mathrm{~kW}$ & $750 \mathrm{~V} / 187.5 \mathrm{~kW}$ & $480 \mathrm{~V} / 140 \mathrm{~kW}$ \\
\hline Voltage/Power & $600 \mathrm{~V} / 75 \mathrm{~kW}$ & $500 \mathrm{~V} / 200 \mathrm{~kW}$ &
\end{tabular}

Slow chargers are the ones that are the home chargers or level 1 charger which are rated up to $3 \mathrm{~kW}(16 \mathrm{~A})$. The fast ones are the level 2 rated 7-22 $\mathrm{kW}(32 \mathrm{~A})$ and are used in public spaces like parking lots of offices etc. [23]. This paper tries to review the ultra-fast charging, so only connectors available for rapid charging will be reviewed. $\mathrm{CHAdeMO}$ or CCS charging standards are used by rapid DC chargers providing power at $50 \mathrm{~kW}$ (125 A) [24]. An EV is charged to $80 \%$ in 20 min by both the chargers contingent upon the battery capacity and initial SoC. $100 \mathrm{~kW}$ or more rates are provided by Ultra-Rapid DC chargers. Typical rates being, $100 \mathrm{~kW}, 150 \mathrm{~kW}$, or $350 \mathrm{~kW}$, although the battery can charge in other maximum speeds between these numbers $[19,20]$. However, the increasing battery capacity of newer EVs are helpful in providing a low charging time with the help from these upcoming models of rapid chargers.

The Supercharger network provided by Tesla, provides rapid DC charging to Tesla drivers via a Tesla Type 2 connector or a Tesla CCS connector based on the model. A $150 \mathrm{~kW}$ charge rate is possible using these connectors.

\section{Power Electronics}

The power electronics circuitry for XFC stations can broadly be classified into two categories [25-36]. AC to DC and DC to DC.

\subsection{AC/DC Rectifier Stage}

Most XFC charging stations are $\mathrm{AC}$ as the conversion technology is more reliable and tested. The prevalence of AC grid is another reason. As of February 2021, 23,277 number strong Supercharger network is deployed by Tesla with an average of 9 chargers per station. North America has 1101 stations, 592 and 498 in Europe and Asia respectively. All of them being AC/DC stations [6]. Literatures suggest that there is an array of topologies for rectifiers for $\mathrm{AC}$ to $\mathrm{DC}$ conversion. However, while designing the charging station, several factors are to be considered. The voltage level, the number of ports, the bidirectional power sharing etc. As mentioned before, the AC to DC technology being a prevalent one, many experimental technologies are used, but the success of those is not exactly guaranteed. Therefore, the Pulse Width Modulation (PWM) rectifier and Neutral point clamped rectifier are the tested and dominant technology [30].

\subsubsection{Three Phase PWM Rectifiers}

The diode bridge rectifiers are cost effective, robust, and easy to install but the operation is not quite smooth. The diode bridge is high in terms of loss. The three-phase bidirectional PWM rectifiers were introduced [30] to solve the problems that the diode bridge rectifiers had, like the high input current harmonics that absorb reactive power from grid. Consequently, only transfer of power from grid to load happens the in case of diode bridge rectifiers as the input power factor becomes small. Low THD, sinusoidal network current and unity power factor are the key advantages of three phase PWM rectifier. Three-phase PWM rectifier charges the battery when in rectifier mode. As demonstrated in 
Figure 3 [30], in inverter mode, power is transferred to the grid by the three-phase PWM rectifier.

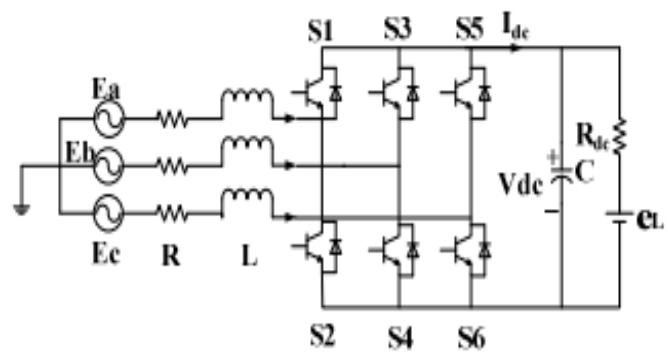

Figure 3. A three phase PWM rectifier [30].

Figure 3 shows the topology of three phase PWM rectifier, which is composed of three phase inductance, three-phase IGBT bridge, the capacitor, and the DC load. With a voltage balanced three-phase input, the PWM rectifier is equivalent to a single-phase circuit. The four-quadrant operation of PWM inverter is as follows, the PWM rectifier only absorbs inductive reactive power from the grid on quadrant 1 . It operates to achieve a unity power factor rectifier control on second quadrant. The rectifier absorbs capacitive reactive power from power grid on the third quadrant. On the fourth quadrant, it can achieve unity power factor active inverter control. Its bi-directional power flow capacity makes it appropriate for charging stations as it ensures a complete $\mathrm{V} 2 \mathrm{G}$ operation.

\subsubsection{Neutral Point Clamped Converter}

Neutral Point Clamped (NPC) converters are constructed of 12 IGBTs and six parallel diodes. As the name suggests, the neutral points of the converter legs, each consisting of four IGBTs and two parallel diodes, are connected in neutral point clamped converter. Higher three-phase grid power quality, low total harmonic distortion (THD), reduced switching frequency, High voltage (HV) and medium voltage (MV) operation, smaller transformer ratio and scalability etc., are the key attractive features for the adaptation of NPC converters in charging stations.

The addition of a voltage balancing circuit proves useful in this regard. A three phase three level neutral point clamped converter [36] is illustrated in Figure 4 [36].

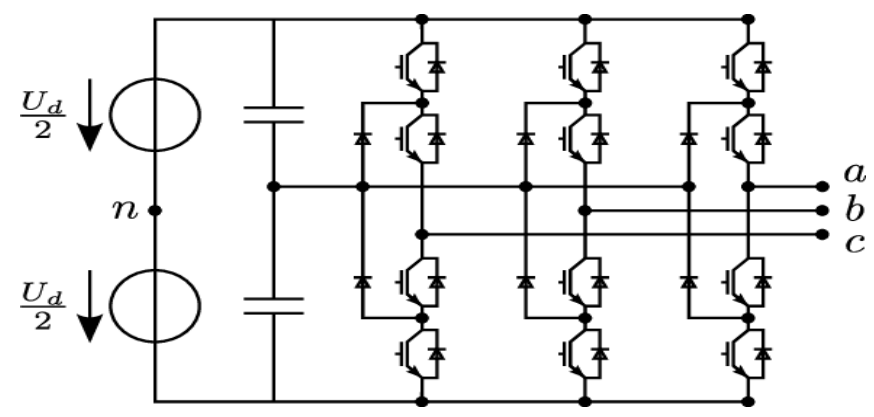

Figure 4. A three phase three level neutral point clamped converter [36].

With the addition of a balancing leg, neutral point clamped converter can also serve as an interface to the bidirectional DC bus in a DC grid making it useful in both MVAC grid and DC grid applications. The lower ripple in the output current and reduced output voltage transient will reduce the filtering and isolation equipment, thus reducing losses. As DC voltage has only two phases, the serial connection of DC capacitor is easily supported without any additional circuit for leakage current compensation. Table 3 presents a comparative view of two and three level PE converters for charging applications. 
Table 3. Pros and Cons of Inverter Architecture.

\begin{tabular}{ccc}
\hline & 2 Level PWM & 3 Level NPC \\
\hline THD of output current & High & Very low \\
Stress on active and passive devices & High & Low \\
Power Density & Low & High \\
Bidirectional & Yes & Yes \\
Conduction Loss & Low & High \\
Switching Loss & High & Low \\
Efficiency & Low & Very high \\
Cost & Low & High \\
Control & Easy & Mid \\
Input inductor size & Large & Low \\
Thermal management & Easy & Difficult \\
\hline
\end{tabular}

A few other lesser used topologies are also highlighted in this section. To attain a higher power factor and lower harmonic distortion, Vienna rectifiers are an efficient but lesser used concept. Figure 5 [37] shows the architecture of Vienna rectifier. Only one active switch per phase makes this topology easier to control.

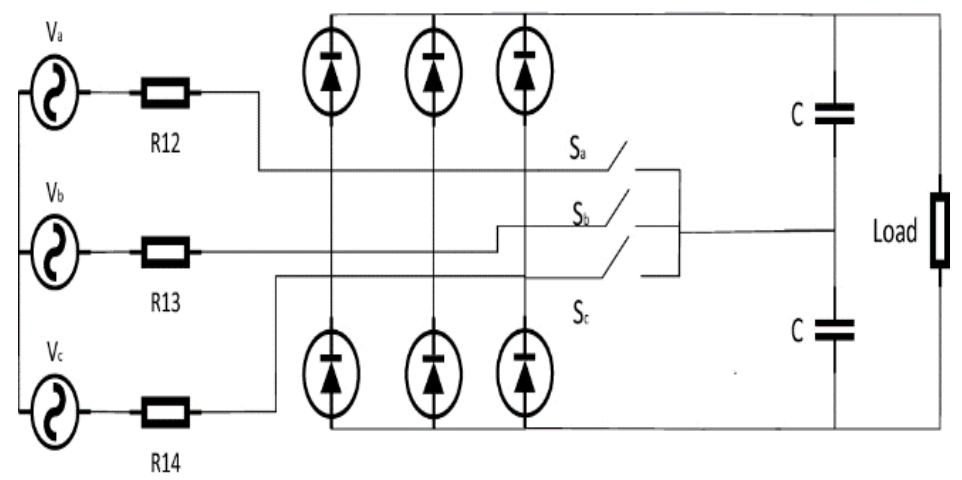

Figure 5. Vienna Rectifier [37].

It is in a way a PWM converter with the boost inductor playing a meaningful role to correct power factor. Whenever the switch is $\mathrm{ON}$, the energy is stored in inductors and transmitted to diodes when OFF [37]. The absence of neutral point makes the switching control easier as no neutral point current problem exists.

As shown in Figure 6 [37], the matrix converter uses an array of bidirectional switches which allow high frequency operation. Although it can improve power factor and reduce the harmonics in line current, the implementation of too many switches makes it impractical to use in charging scenario.

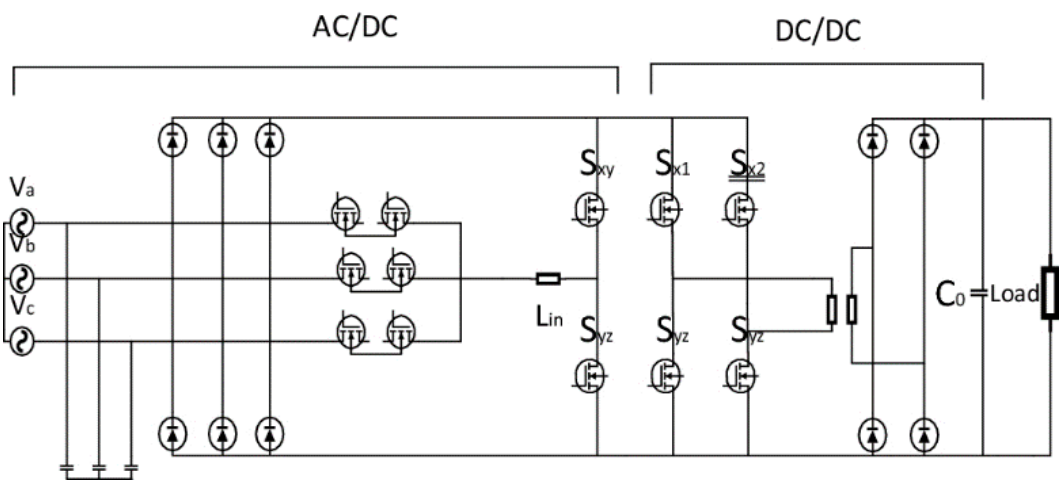

Figure 6. Matrix Converter [37]. 
Among all the topologies mentioned in this paper, level 3 NPC is the most viable topology to use in XFC. It has a robust structure, low THD of output current and the size of inductor is small. Although it has the problem of neutral point current balancing, that can be averted by programming the correct sequence of switching using a finite control set model predictive control. Upcoming research in this area is promising.

\subsection{DC/DC Converter Stage}

HVDC and DC is a quickly evolving technology. The one advantage of DC is the choice of one single interconnection to the utility through the front end central. This increases the load diversification. Load diversification leads to different levels of charging schedule corresponding to the state of charge $(\mathrm{SoC})$ of the battery. This leads to lesser cost of converters which reduces the system installation cost. The nonexistence of reactive power in DC systems make easier control technique. Easier islanding is possible due to one single interconnection to the main grid. The opportunity to process partial power thus reducing the system loss and converter cost is another main advantage of DC distribution system [38-50].

The challenges of DC-DC conversion lie in the production of hundreds of amperes of current because the converter is low voltage and high power typically $400 \mathrm{~V}$ DC or less. These large currents have several disadvantages including thermal stresses on active and passive components which reduces the efficiency and longevity of the components. Plus, EMI emissions make the packaging technology harder, making the converters large and overpriced. Thus, an efficient, compact, and cost-effective DC-DC converter design is needed.

The DC microgrid must interface with several components viz multiple DC-DC chargers, Renewable Energy System (RES) and energy storage while providing grid stability and rapid charging. The main topologies of DC-DC charging can be subdivided into nonisolated and isolated DC-DC converters as discussed below.

The basic difference of non-isolated converter topology is the placement of a capacitor in the input DC side and on the output DC link. When output to input voltage ratio $\left(\mathrm{V}_{\mathrm{o}} / \mathrm{V}_{\text {in }}\right)$ is lower than one, the converter works in discharging mode and in charging mode for vice versa. In case of DAB converters, they deliver power regardless of input output ratio.

\subsubsection{Non-Isolated DC-DC Converter}

There are three potential non-isolated DC-DC power electronic interfaces topologies which are used in EV power management systems. The half bridge, the SEPIC and the Cuk converter [38]. The half bridge converter has one leg connected with the LC circuit, and the SEPIC converter has an extra leg in boost converter with LC circuit. The Cuk converter replaces that with a freewheeling diode. As this paper tries to focus on XFC charging, only half bridge converter is worth discussing here.

There are several pros and cons of each converter over the other, making them application specific [40]. The half bridge converter has one inductor, so the losses are far low. Due to lower inductor conduction and lower switching and conduction losses on active components half bridge has higher efficiencies. The energy handling requirement and the core plus conduction loss is almost like Cuk and SEPIC converter.

The main disadvantage of the half bridge converter when operating as a boost converter is the discontinuous output current which affects the function of the output capacitor. After reviewing three types of non-isolated DC-DC converters [42-44], the half bridge can be recommended as the most efficient for XFC operation. A half bridge converter can be seen in the Figure 7 [43] 


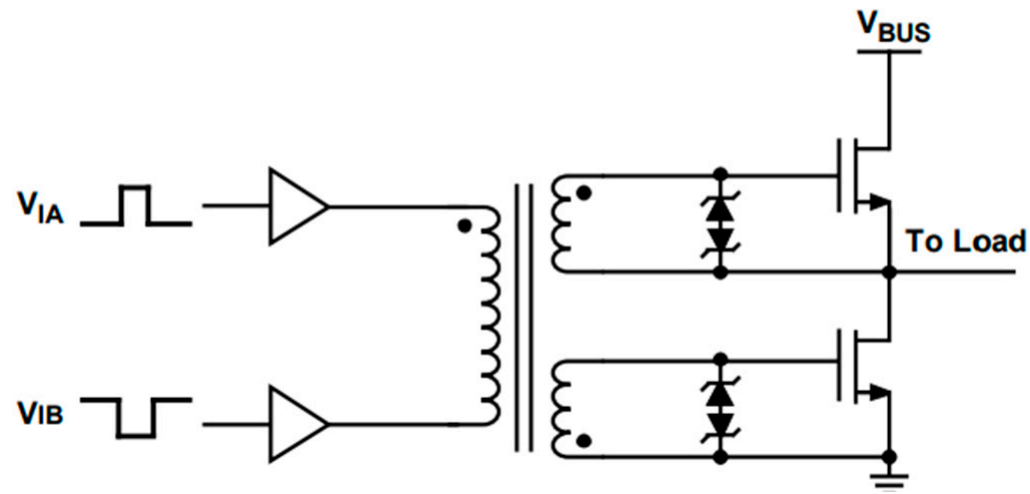

Figure 7. Non isolated DC-DC architecture-Half bridge [43].

\subsubsection{Isolated DC-DC Converter}

High power isolated bi-directional DC-DC converters are most used converters as they provide galvanic isolation, $\mathrm{V} 2 \mathrm{G}$ capability and have a reduced carbon footprint on the environment, as well as being cost-effective [45]. There are different topologies of isolated DC-DC converters operating in many areas. Full bridge, half bridge, push-pull, to name a few. However, the charging stations need a converter that is compact and has high power handling capability. Therefore, the LLC, and DAB converters are primarily used for this application.

LLC

The LLC converter uses a high frequency transformer instead of a high frequency capacitor. This increases battery life [43-46]. The criteria for choosing the converter topology include high reliability, efficiency, and low cost. Figure 8 shows the schematic for an LLC converter for XFC application.

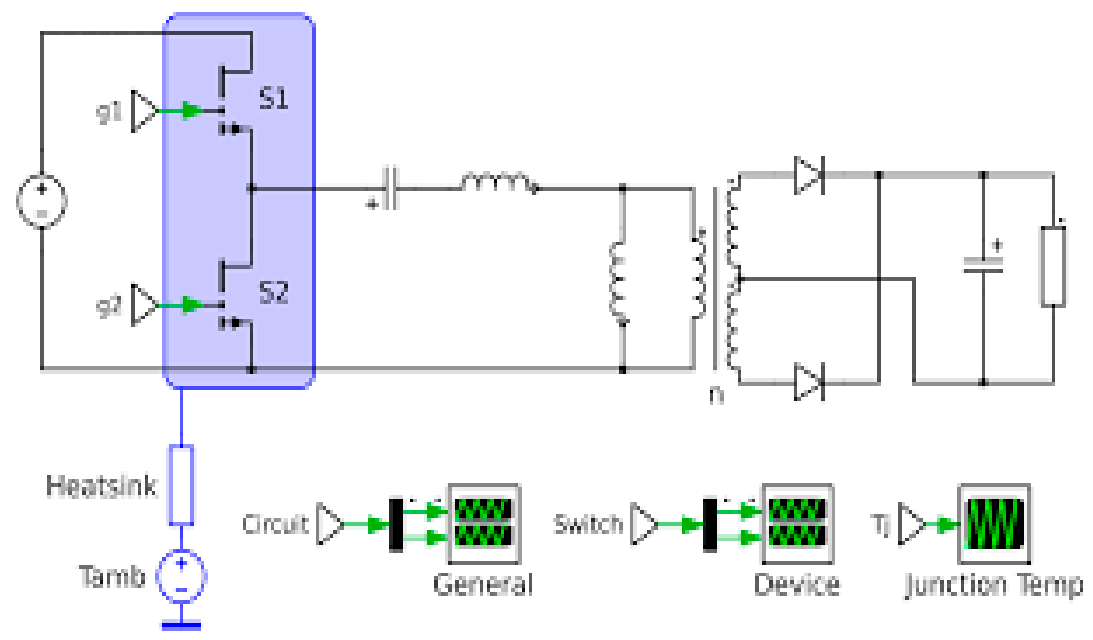

Figure 8. An isolated LLC converter for charging station applications [46].

LLC converters are also in widespread use for its high efficiency at resonant frequency and its ability to regulate the output voltage during the hold-up time in telecom industry. The output voltage is constant, but a significant drop in input voltage might be noticed in a short time. Fuel cell applications also use these converters.

A prototype converter in [45] that has been designed with switching frequencies of $50 \mathrm{kHz}$ in the boost stage and $300 \mathrm{kHz}$ in the LLC stage, it gives experimental results of efficiency more than $90.2 \%$.

LLC converter have added advantages like the efficiency is superior at low and medium load because the switching loss is little. This converter is useful in bidirectional applications because it has a bidirectional power flow in regards to the input and output 
conditions. This is what is essential for V2G applications. An isolated LLC converter [46] is shown in Figure 8.

\section{Dual Active Bridge Converter}

A symmetrical circuit topology is used in dual active bridge converters (DAB) where two voltage source converters are inserted on top and bottom of a high frequency transformer with a unity turns ratio. The DC-DC converter is characterized by the less switching losses on diodes and less ripple voltage/current stress on the two dc capacitors. The DAB converter is capable of zero voltage switching making it applicable in a wide range of power ratings depending on the available power device's switching frequency [46]. A Dual Active Bridge converter is illustrated in Figure 9 [4]. However, their conversion efficiency is not commendable at high-frequency operations [24].

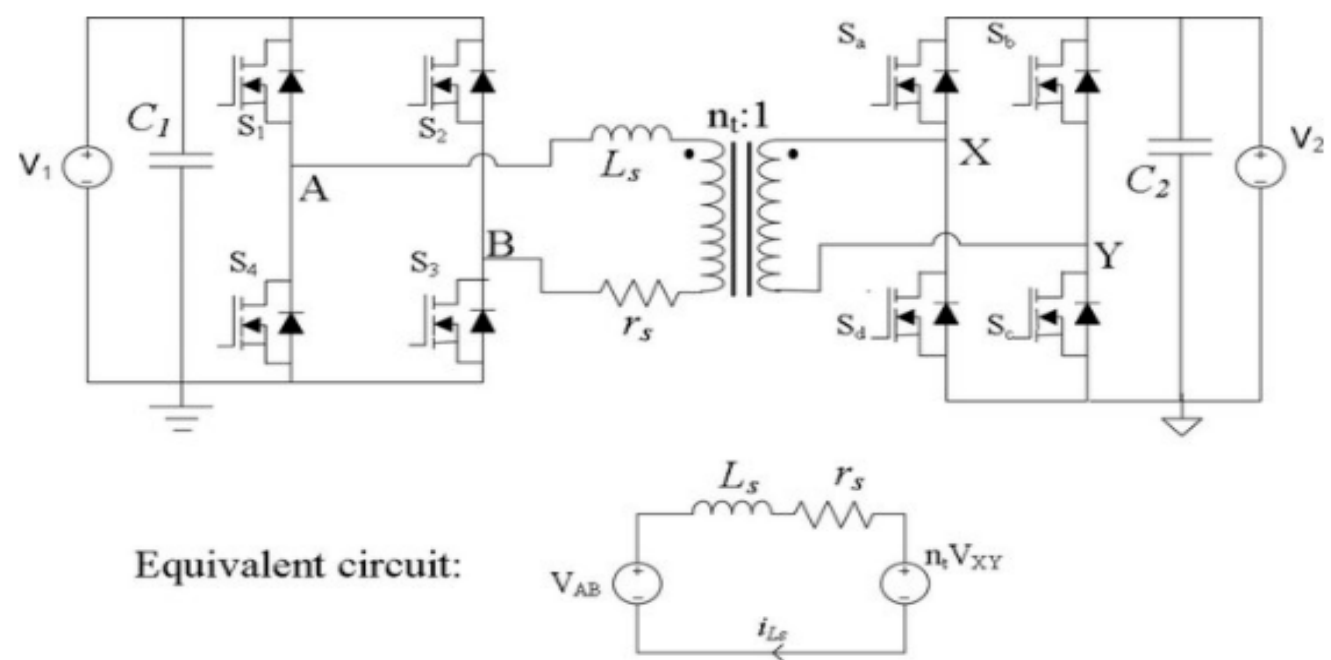

Figure 9. A Dual Active Bridge Converter for Charging Stations [48].

Series and/or parallel connections of multiple DAB dc-dc converters would make it easy to expand the voltage and/or current ratings such as the converters were operating as a single high-power DAB DC-DC converter.

They can also perform well with added ESU technology [49]. In particular, the input series and output-parallel connections show considerable promise as a DC-DC converter for medium-voltage high power battery energy storage systems and an interface circuit between two DC power networks with different DC voltages.

When the next generation SiC-MOSFET modules come across, the conversion efficiency of a well-designed DAB DC-DC converter is expected to be higher than $98 \%$ in a wide range of power ratings.

The power electronics topology selection not only depends on simple facts like, the output power rating or maintaining grid stability by frequency control, but also on the voltage to grid reactive power operation, the interfacing of electric vehicles and the impact on energy storage units etc. However, power electronics is a very competitive field and there are a multitude of topologies in research and development stage, the topologies discussed in this section have been investigated keeping these aforementioned factors in mind.The comparative analysis of the DC/DC topologies can be found in Table 4 below. 
Table 4. Pros and Cons of isolated DC/DC topologies [32-42].

\begin{tabular}{ccc}
\hline Type & LLC Converter & Dual Active Bridge \\
\hline Device stress & Higher & High \\
Transformer Rating & High & Low \\
Input and Output capacitor current & High & Low \\
Operation & Bidirectional & Bidirectional \\
Conduction Losses & High & Lowest \\
Turn ON switching loss & ZVS & ZVS \\
Turn OFF switching loss & Low & High \\
Total losses & Low & Medium \\
Control Complexity & Moderate & Simple to complex \\
Wide battery voltage, fixed bus voltage & No & Yes \\
Paralleling modules & Intensive & Easy \\
Switching frequency & Fixed/high (Si/Sic) & High \\
\hline
\end{tabular}

\section{DC Fast Charging (DCFC) Station Cost Analysis}

Investing in DCFC as a promising technology might be tricky as the high voltage generation, operation and equipment have high costs. The ways to mitigate these are discussed in the several section of this paper. Nonetheless, a look into the cost of operation of a DC-XFC is analyzed in this section. Utility demand charges based on highest monthly peak power drawn by the customers, including charging stations. This is done to recoup the fixed cost of generation, transmission, and distribution [12]. According to 2020 tariff data, demand charges can range from 2-90 USD/kW [5]. To put the cost-efficient model into perspective, a practical case needs to be examined. Tesla recently installed 56 numbers of V3 supercharger in a charging station in CA, making it the largest charging station by them to date [4]. The convenient location near a store and restaurant makes planners think that it will be utilized enough to gain profit. Most of the charging stations are not utilized more than $12-18 \%$ of its capacity but power calculation of such a charging station is done at 100\% occupancy for $24 \mathrm{~h}$ a day for cost analysis purposes [38]. The $250 \mathrm{~kW}$ charger being utilized $24 \mathrm{~h}$ a day for 365 days will need $2190 \mathrm{MWh}$ of power. The on-peak times can be given as $12 \mathrm{PM}$ to $7 \mathrm{PM}$ during the summer months of high temperature and $8 \mathrm{AM}$ to 3 PM during the colder months. The average per unit cost of electricity in California is 16.67 cents $/ \mathrm{kWh}$ [5]. Depending on the location and the tiers decided by PG\&E the price of electricity can be 30 to 50 cents in peak hours. Thus, for $2190 \mathrm{MWh}$ power the cost of the peak hour electricity becomes 191,625 \$USD/year for 30 cents/kWh or 319,375 USD/year at 50 cents $/ \mathrm{kWh}$, for $7 \mathrm{~h}$ a day, 365 days [51].

However, solar energy costs from 6 cents/kWh to 10 cents/kWh [51]. Replacing the grid power with solar generated power, the charge per day, for $7 \mathrm{~h}$, will be $63,875 \mathrm{USD} /$ year or $38,325 \mathrm{USD} /$ year for $7 \mathrm{~h}$ a day, for 365 days, for prices $10 \mathrm{C} / \mathrm{kWh}$ and 6 cents $/ \mathrm{kWh}$, respectively. Thus, giving savings from 153,300 USD to 255,500 USD per year for different rate and tariff types [51]. A similar approach replacing solar with energy storage system (ESS) is discussed in [12]. The capital cost of Solar Energy station might be paid off in a year or two with the savings made in tariff [12]. The example of California cited in this section represent a large number of global populations. In Europe and certain parts of Asia, the incident solar intensity is lower than that of California. However, the cost of electric power in these parts of the world is much higher than that of California. Thus, even with lower intensity, the cost of electric power generated by solar will be lower than that of conventional grid. There are some parts of the world where solar intensity is very low, but in these places lower cost wind generated green electric power is available.

\section{Impact on Sustainability}

Sustainability plays a big role in today's scientific world. With the spread of internet and social media, people have greater access to knowledge which has opened their eyes to a countless variety of issues, and global warming is one of the major ones. This climate is for the humanity to preserve and in order to do so, the first step is to reduce pollution. The 
number of pollutants releasing factors are many but can be broadly classified into three types, viz vehicle emission, industrial emission, and personal usage emission. The vehicle emission can be easily reduced with the widespread usage of EV.

The charging station is useful in this interest to make the EVs functional. It is up to the general customer to adopt EVs and the utility grid to inject more renewables into grid so that the energy EV draws is clean [52-68]. But fast charging stations are rarely found at home. It is either set up by the EV manufacturing company or by any corporation for their employees from any individual charging station manufacturers like Chargepoint or Wallbox [55]. Therefore, company policies and the ethical sourcing of energy for on campus charging will play a big role in shaping the future of sustainability for XFC.

\section{The Protection of EVCS}

An understanding of charging station configuration and its fault behaviors is important to develop a comprehensive protection system. This section sheds light on the charging station protection architecture and the rooms for improvement. Tesla has recently opened a $250 \mathrm{KW}$, with 56 chargers in a charging station [51-54]. A charging station is basically a small HVDC system. That means the protection architecture is quite similar [61]. The power architecture of charging station is shown below.

Most of the charging stations are connected to the AC grid. Although a fully DC grid will be the future of power system but currently the scenario is fully AC with some charging stations doing 100\% renewable penetration. The grid connected charging station also provides support to the grid thus carrying a bidirectional power flow. In a nutshell the charging station has two main functions which are fast charging of EVs and Grid conditioning capability. Fast EV charging station can work as a shunt active device to achieve harmonic filtering, reactive power compensation and imbalance compensation with grid conditioning capability [63].

Figure 10 shows high power galvanically isolated inverter converts the grid AC power inro DC. The DC bus should be equipped with ultracapacitors for ripple power filtering and temporary energy storage. High energy losses occur in this power architecture. The EV batteries get charged through the DC/DC converters between the DC bus and EVs. Thus, the charging station protection architecture itself is DC/DC protection.

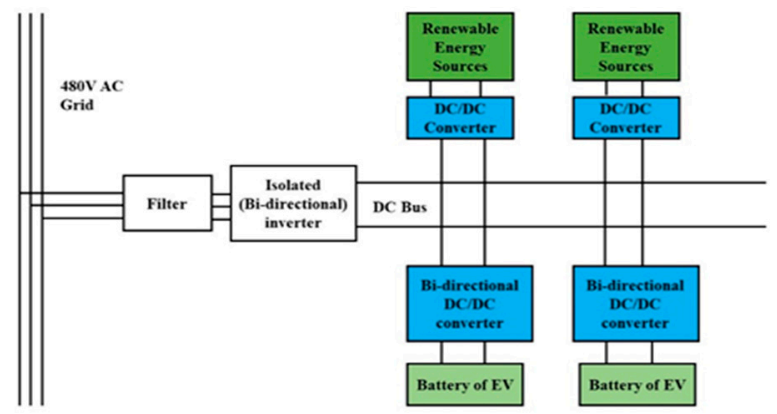

Figure 10. Power architecture of AC EVCS.

The types of possible faults in the charging station needs to be discussed in a similar way as the HVDC transmission system [55]. In all reality the charging station is a nano HVDC grid with all its functionalities. The types of faults detected in an HVDC system are overcurrent, overvoltage, line to line and line to ground faults. The HVDC equipment have limited fault tolerance ratings compared to AC equipment. DC technology is coming off age and the limitations of DC protection will be discussed in the later parts of this section [64]. The types of DC faults that might occur in an HV fast charging station are as follows: 


\subsection{Line to Ground Fault}

Line to ground fault occurs when the positive and negative lines are shorted to the ground. Faults may occur in overhead lines when lightning strikes the line [54]. That might cause the line to tear, break and touch the ground creating a dangerous fault. In a situation like this where the external system is heavily disrupted, the fault is permanent in nature and the protection devices are obsolete. The only way to repair a heavily impaired line to ground fault is to isolate the line and repair with the help of technicians. Other than lightning, storms or any external forces which might cause the trees to fall on the line may also cause line to ground fault. Sometimes it is caused by a small object, and it can be restored once the disturbing object is removed without causing much disruption. The line must be taken out of service until the fault path is cleared. In theory, underground cables or encased systems like charging stations are completely protected from line to ground faults. However, they still can occur due to improper installment of the casing, breaking of the system by external force or attempt to theft of charging station equipment or many such things. When this happens the broken cable insulation will provide a path for line to ground fault. In either case this will require a complete shutdown of the station and costly repair. The line to ground fault rapidly discharges the capacitor to ground from the faulted pole end. This causes a phase imbalance creating high currents that might damage the capacitors and power electronic converters in the system.

\subsection{Line to Line Fault}

The occurrence of line-to-line fault in an enclosed environment like the EVSE is rare. The failure of switching devices might cause the lines to short [62]. The switching fault is independent of the converter connection or rating. It might cause the positive and negative bus to short in the encasement that could generate a fault that is mostly temporary.

\subsection{Overcurrent}

Both kinds of faults mentioned earlier might be subjected to overcurrent fault if the appropriate protection is not there [62]. In other times, an overcurrent fault might occur when the system is overloaded. The two terminal systems are subjected to overcurrent fault in case the converter is overloaded because of the fault in another part of the system. For instance, if multiple converters are engaged in a series or parallel connection to generate the high-power ratings needed for the fast-charging stations. If one converter fails, then the others will be overloaded thus generating overcurrent in the system. Thus, the protection devices should intelligently drop the faulty line and create a shunt resistance path to avoid damage of the remaining converters. More on this will be discussed in the equipment subsection. When similar fault happens in power grids, black out is the smartest thing to do to avoid spread of the fault throughout the network.

\subsection{Overvoltage}

The types of protection devices are two. AC and DC. AC devices are installed at the grid to charging station interface which isolates the charging station in case of a fault in the network. DC devices are installed inside the charging station to regulate the system in case of the aforementioned faults that might harm the entire set of equipment building the individual charging station or the network of charging stations in a facility. The devices used for these both kinds of protection are elaborated below $[63,64]$.

\subsection{AC Circuit Breakers}

For cost effectiveness the charging station node can be easily protected by an AC circuit breaker. It is readily available and replaceable. But AC circuit breakers have mechanical parts that take long time to repair. The charge of DC capacitors will be monitored back to the standard relay that observes over/under voltage/current. At the onset of fault, capacitors will discharge causing the voltage to decrease and the current will increase over 
the rated value. Once the relay senses the anomaly, it will trip the circuit breaker protecting the charging station network.

\subsection{Protection}

The rest of the charging station utilizes DC protection in form of fast acting solid state circuit breakers and switches [64]. The monitored voltage and current through each line will send the necessary signals to the respective solid-state device. The fast-acting DC switch will open once the fault is detected. This type of fault can be cleared without interrupting the entire network as each line has its own solid-state device. This type of mechanism is also more expensive due to the presence of switches in all the lines. Furthermore, if the device is placed in a positive line, it cannot detect the fault in negative like other switches. DC protection devices also protect against overvoltage by implementing a chopper circuit.

Solid state circuit breakers (SSCB) are quickly emerging technology that suits well with high efficiency DC applications like fast charging stations. Fault clearing operation needs to be faster, and the advanced semiconductor technology is helpful in this regard. The increased research in the material and topology of semiconductor devices has stimulated an increased development in SSCB. Wide Band Gap (WBG) devices are used in SSCB, which have robust material properties that make their operation at higher temperature, voltage and switching speed easier. Their low conduction losses per specific die area are also worth mentioning. For this reason, authors suggest that a substantial amount of WBG research should be redirected at SSCB applications.

\section{Reliability}

The reliability estimation of EV fast charging system is another aspect to consider before proceeding. A thorough reliability estimation model must be developed to ensure a robust fast charging infrastructure.

First the voltage, current, and thermal stresses on semiconductor switches must be analyzed based on a mission profile through a comprehensive mathematical and simulation model. It should propose the lifetime prediction and the reliability analysis from the data provided by thermal stress. Thus, this information can be used in a notional fast charging system planning to ensure a long life of operation [65].

More on this has been discussed in the cyber security and discussion section. The impact of implementation of $\mathrm{AI}$ in a reliable and secure charging network remains an area of interest and those sections shed ample light on it.

\section{Cyber Security for XFC}

Electric vehicle charging stations will become a part of the national critical infrastructure and, therefore, a target for attack. It will be a part of both the transportation and financial infrastructure. This will make it attractive to numerous types of attackers [66]. The modified attack taxonomy on automobile security can be found in Figure 11 [67].

In addition to the typical attack sources, it should be noted that electric vehicles present a threat to some very well-resourced adversaries. It is a revenue threat for gasoline producing countries including but not limited to, Russia, Iran, and Saudi Arabia. Attackers from those countries will be strongly motivated to attack charging networks and make Electrification of Transportation (EOT) unattractive. For some of these countries, it is often unclear whether the attacks are only criminal, or state sanctioned. Groups associated with Iran have already attacked computers associated with Saudi oil production [68] showing both their willingness and ability to attack critical infrastructure to safeguard their petroleum revenue stream. This should not be surprising, since US officials planned in the past to destroy Iranian power infrastructure [69]. Russian entities are frequently the source of computer security incidents and attacks on critical infrastructure. However, it is often difficult to say if these attacks are purely criminal, sanctioned by one of the many intelligence services involved in network hacking (GRU, SVR, FSB, etc.), or some combination of the two. 


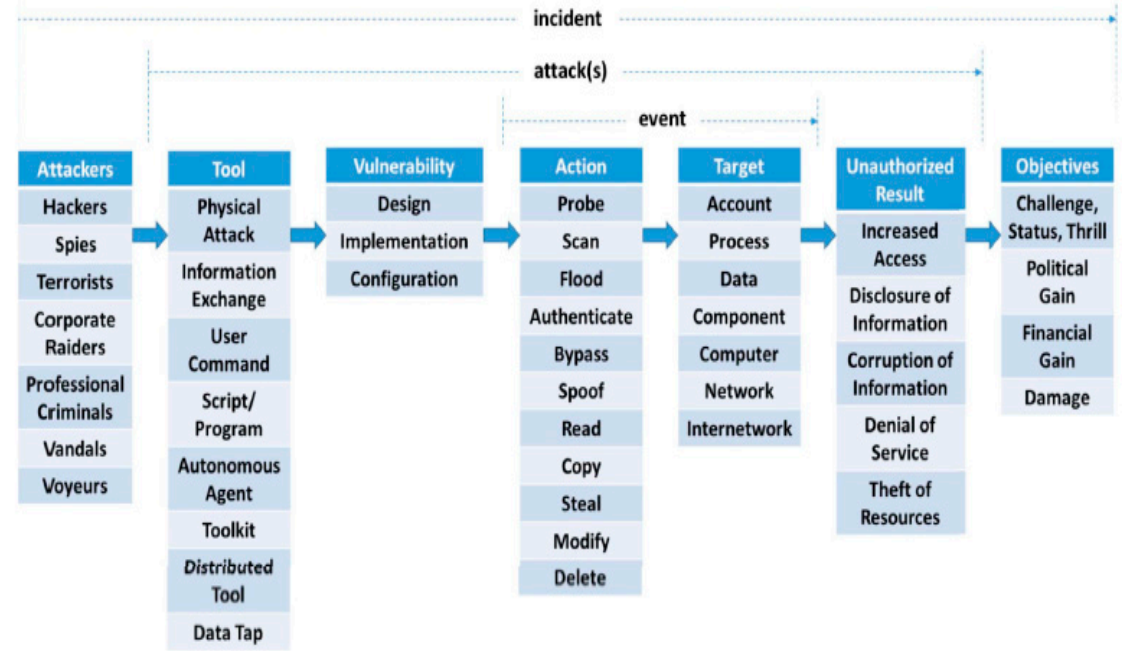

Figure 11. Modified attack taxonomy for Power System threatening the charging network [67].

A ransomware attack initiated by Russian hackers shut down everything from supermarkets in Sweden to kindergartens in New Zealand earlier this July 2021 [70]. This included the gasoline pipeline supplying the US East Coast. It is worth noting, that the weaponized software behind most Russian software was originally developed by the NSA and used by the Russians only after compromising NSA internal security. This was established by Israeli operations that compromised GRU internal security [71]. These incidents illustrate the vulnerability of US critical infrastructure to compromise by well-resourced opponents.

The connections of charging infrastructure to automobiles are particularly concerning, due to the relatively poor security of automotive systems. In general, automobiles have multiple ECUs communicating over the internal CAN Bus. The CAN Bus has notorious security problems. Devices are not authenticated. Communications are in clear text. All messages are easy to spoof. This means that if any ECU is compromised all vehicle functionality is at risk. Originally, it was assumed that the automobile would be a closed system. Unfortunately, later developments allow EV communication bus to be accessed via numerous wireless network technologies. To start the protection, charging stations should assume the vehicle they connect to is compromised and insecure. They will need to assure end-to-end security by having communications endpoints in the car be hardened and tamper-proof. These end devices need to authenticate themselves using a separate public cryptography secret key for each automobile. It would be advisable to have these devices be inside a faraday cage, have their own internal power supply, and delete the authentication key, should the faraday cage be compromised. Heat sensors that verify that the device temperature never goes beneath a specific value is also worthwhile to avoid forensic memory analysis by leveraging a well-known but rarely used variant of the evil maid attack [71,72].

Several times in the past decade Chinese cybercriminals have breached the cloud and taken valuable information for using against the US government [73]. This is often related to supply chain attacks. Current software practice uses software from other vendors to construct new systems. Unfortunately, if the up-stream supplier has been compromised, then all security guarantees are off. Research is sorely needed to find ways of isolating the security implications of software component use and re-use. This will require a clean-slate redesign of software development and integration models.

To alleviate this problem, apart from imposing strong regulations to data acquisition and software terms and agreements, another approach might be to change the power system network completely to DC power. In addition to capital cost, and power savings, DC networks, have desirable characteristics for cyber security. Mainly, individual networks are isolated from the global system. Sandworm APT's attack on Ukraine [74] would not have been possible in a local network of DC power. A local DC network should 
be able to stop cascading failures. Non-intentional disruptions would easily be isolated and contained but isolating intentional disruptions would still be hard. For example, ransomware could still disable individual DC networks, but the reach of the attack would be limited. Decentralizing control of the grid would force attackers to compromise many control centers that are independently maintained. Attacking the individual DC power network is also less attractive since disabling isolated neighborhoods is less useful than disabling a whole country.

A major issue is defining standardized local power networks. Clear standards and well analyzed software will help to create secure systems. This is countered by the legitimate concern that monocultures where many systems run identical software are riskier. Once a vulnerability is found, the whole grid is immediately compromised. Decentralization has risks, too. When many systems are individually installed, configured, and maintained, the risk of components being incompetently maintained grows exponentially. The decentralization of the Local DC power networks architecture has desirable characteristics as well as risks. However, for nation-state attackers, note that the amount of effort that is currently being used to disable an entire country would only disable a single house, or neighborhood. While wide-spread attacks would be possible in theory, they would most likely no longer be financially attractive for foreign governments.

\subsection{Threats in Charging Network during Billing}

Some potential threats are discussed below that encourages the integration of security measures in charging infrastructure right from the beginning. The threats range from vehicle connection to communication and specifics of vehicle charging.

A passive attack that might gain personal information or more for additional attacks by intercepting information. A physical or logical access to the communication connection is required to the adversary $[75,76]$. Both charging station to car and charging station to grid communication can be intercepted as shown in Figure 12 [75] below.

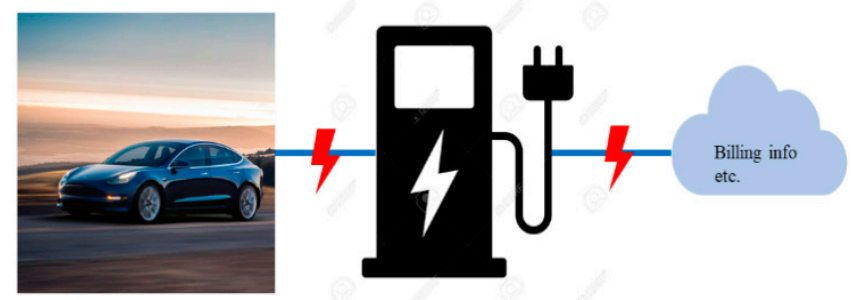

Figure 12. Interception of information via charging stations [75].

The loophole in the system begins when the radiation of the communication transfer to the adversary when the physical or logical access to the communication connection is in closer vicinity to the communication rather than having direct physical address. Powerline communication of PLC is one such technology that comes to mind. As shown in the figure above the valuable information that can be stolen ranges from tariff data, billing info or charging status. For billing, it is a solved problem with two solutions: credit card companies or cryptocurrency. Credit card companies solve the problem largely by using lawyers. The problem is that users lose individual control and privacy. Crypto-currency is an attractive alternative, but can make law enforcement more difficult and current versions are bad for the environment.

\subsubsection{Man-in-the-Middle-Attack}

This refers to the attack that consists of the modification of the information intercepted from the vehicle and supplying to the vehicle or grid to mess up the synchronous operation. This refers to the attack that consists of the modification of the information intercepted from the vehicle and supplying to the vehicle or grid to mess up the synchronous operation [76-78]. Such as the case of charging spot being provided wrong tariff 
information by the adversary. It is easily accomplished by a modified charging cable. It can be visualized in the Figure 12 [75].

As shown in the Figure 12 above another scenario is the usage of a fake charging spot in between the real spot and the vehicle. Thus, the customer connects to the fake spot and thus their assets get stolen. The customer does not get any hint because the fake charging spot is connected to a communication router to a real charging spot. Another threat is the theft of energy while the customer is charging the vehicle, a fraction of the total energy only gets to the vehicle, and rest gets stolen by the fake spot while the customer pays the full price of the energy.

Another facet of this kind of theft is that the adversary manipulates the energy path not the communication path, the communication path remains untouched, and the customer doesn't have a clue of the theft. This made the authors strongly suggest research on the dire need of connecting the information flow and the energy path.

\subsubsection{Other Types of Threats}

Another means is the transaction falsification in which the customer receives extra bill for fake energy by intercepting their information or the utility might charge them extra for modified information that makes them think that the customer used that energy.

The attack might also happen from within the vehicle. The owner might connect to a charging network and inject or modify application-level traffic as an attack. Sometimes this might happen to no fault of the owner through a malware or faulty software component. Various apps installed in mobile devices which communicate with the car are also a vulnerable node [69].

As the previous point remains valid here, the customer might be the adversary and might use pirated or replacement parts to acquire, modify or control information affecting the charging infrastructure and the EV itself. Several steps including the participation of ethical hackers is required to alleviate the threats in charging network [73].

\subsection{Moving Target Based Defense}

The battery electric vehicles in the grid increase the power capacity and networking requirements and create a threat in the charging system. Therefore, the increase in adversarial attack calls for security measures to be taken in the involved cyber physical system. The battery management system (BMS) is the first line of defense against cyber-attacks, as the battery is the first line of contact between the grid and the vehicle. A compromised vehicle may contaminate the entire charging network. Therefore, the BMS security is imperative. A moving target defense (MTD) based novel approach must be implemented for the security of the vehicle BMS [79]. In literature there are several studies on the security hardened BMS which aims to increase the security and performance of operations between the charging station, the BMS, and the battery system of electric vehicles has been hypothesized $[69,75,79]$. The redundancies of the controller and feedback design are used in MTD based switching strategy. The acceptable charging performance under attack might be studied from the simulations that model the degree of unpredictability.

To take this MTD based study a notch farther, the security against the adversarial attacks, known as spoofing and replay of CAN bus should be implemented. A charge control strategy is developed for the redundant BMS controllers and observers, which gives promising results without the large calculations of authentication methods. This can be implemented practically for XFC and other CPS and IOT applications under attack.

The threats in charging network are summarized in Table 5. 
Table 5. The Threats in Charging Network.

\begin{tabular}{llll}
\hline Attackers & Target & Type of Attack & Result \\
\hline Spies & Charging Network & Passive & $\begin{array}{l}\text { Stolen Financial } \\
\text { Information }\end{array}$ \\
\hline Corporate Hackers & EV & Active & $\begin{array}{l}\text { Overcharging the } \\
\text { owner }\end{array}$ \\
\hline $\begin{array}{l}\text { Professional Cyber } \\
\text { Criminal }\end{array}$ & Billing info & Passive & Large bill \\
\hline
\end{tabular}

\subsection{Other Mitigation Techniques}

Air gapped network, anomaly detection approaches, big pipes, and traffic filtering etc. are few network security techniques to reduce power Systems cyberattacks [67]. A security technique called air gapped network isolates the vulnerable network from rest of the secured power system. A similar technique can be applied in charging infrastructure where the breached charging point will immediately be cut off from the rest of the station. To take it a notch farther, shutting down the entire car except the battery, so that no communication takes place during charging, might also be a good idea. Anomaly detection approaches are used to detect attacks on power systems networks [64]. However, the detection performance is high if the network is utilized less. Thus, for a big charging infrastructure, this might not be as effective. Network connections viz big pipes with bandwidth that can absorb attack traffic to mitigate the cyberattack on the system are very costly. Traffic filtering is another approach that filters the attack traffic from the normal traffic thus stopping the attack. However, large traffic volume and lack of documentation makes this approach difficult to implement [67]. Other than these technical approaches, strong regulations regarding the data collected by IT companies and the access to that data must be imposed. If there is no financial, legal penalty, industry does not care about customers [80].

For finances, there are two choices, just using credit card companies are a viable option. They have lawyers and know how to find and punish abuser. In addition, they know how to price in losses due to fraud and criminality. Refs. [81-83] The use of crypto currencies the buying and selling of them also expose the system to threat [82].

As mentioned above, DC micro-grid can be isolated and get rid of most vulnerabilities. Using larger grid has many problems [67] including market manipulation [80]. The national grid is very open to attacks by well-funded opponents, including stolen NSA cyberweapons [69]. Since the cyberweapons leverage security flaws that are classified in the USA, there is no way for industry to guard against it. Many recent attacks are supply chain attacks. This means that any flaw in any software used by anyone in the development process can result in a fatal compromise. There is no way to guard against this. This can also include hardware Trojans, since practically all chips are produced in Asia that are controlled by potential global rivals to the USA, hence there is no practical mitigation [71].

Due to the paradigm shift in connected and autonomous vehicle technologies the automakers are introducing the connected autonomous vehicles with self-driving and self-parking features. Therefore, traffic flow prediction (TFP) using Support Vector Data Description (SVDD) model is used to smooth out raw data and enhance filtration points [84] to improve prediction accuracy. Despite using these models to perfect raw data, unexpected scenarios such as extreme weather events or pandemics like COVID-19 might happen. In that case, based on the indoor-outdoor temperature and the subsequent electric power consumption, a data model is generated and developed using TensorFlow framework [85]. A detailed investigation on the electricity consumption and COVID-19 pandemic has been done in reference [86] and a conceptual framework is developed to alleviate the impact of uncertainty in case of extreme scenarios, weather or pandemic alike. Machine learning models with datasets consisting of charging, processed from the workplaces since 2016 to 2018 were gathered in reference [87]. It consisted of a heterogeneous EV fleet of more 
than 1000 vehicles. After processing through machine learning algorithms, a $21 \%$ more charging infrastructure usage was reported [87]. The authors in reference [88] provided a comparative analysis of various supervised, unsupervised, and deep learning methods for EV charging predictions. The findings show that high dimensional datasets were not available due to lack of comprehensive cluster analysis in the charging network. Hence a robust data gathering system implementing AI must be incorporated. The problem of false data injection attack (FDIA) in the BESS operation stage has been discussed in reference [89]. According to the authors of reference [89], different system layers must use applied ML and AI methods for FDIA detection. Methods such as clustering and artificial-neutral-network (ANN) based state estimation forecast are recommended. With enhanced usage of AI in charging network, the power consumption can be regulated, infrastructure can be accurately used, and the security of cyber physical system will be enhanced making EVs attractive to customers.

DC microgrids that are not attached to the global grid are the better solution for security and environmental reasons. Using established credit card infrastructure for payments and following their standards is best. To avoid meaningless death, passing legislations to safeguard the security of consumers is imperative. The cyber threat is a problem that needs sound technical approaches, strong business ethics and stringent government regulations in equal measures, to make charging infrastructure a secure place for consumers.

\section{Transformative Role of Silicon Carbide in DC-Fast Charging}

Silicon devices have dominated the world of power electronics in the last several decades in a wide range of power applications. A large amount of energy is dissipated during conversion steps of $\mathrm{AC} / \mathrm{DC} / \mathrm{AC}$ due to the low electrothermal conductivity of silicon devices. High operating electric field, high operating temperature, high switching frequency, high breakdown voltage, and low losses are several attractive features of silicon carbide devices which cannot be achieved in silicon devices. SiC devices need low output capacitance making it appropriate for high voltage applications. Magnetizing parts like transformers, chokes and inductors etc., are also eliminated or reduced in sizes in $\mathrm{SiC}$ applications. Packaging density gets higher as external cooling is reduced. Due to higher thermal conductivity, silicon carbide devices need smaller heat sink and provide higher system reliability. The weight and load of XFC equipment can be reduced using SiC devices [14]. As the need for cooling decreases, and power density increases, it will reduce charging time as well [14], half the time is estimated in charging for the same power level compared to Si devices. The potential for growth of electrification of transportation is promising by using $\mathrm{SiC}$ devices for XFC.

\section{Maintenance of XFC}

After establishing a charging infrastructure for fast charging, the maintenance and electricity procurement defense is a key aspect of the charging infrastructure's validity. As mentioned in Section 7, the cost is an important aspect of charging station operation, and the grid has an important role to play in terms of setting up new ESR to help the charging infrastructure accessible to the consumers.

The maintenance cost for charging infrastructure generally includes storing charging cables securely, checking the machineries periodically, and keeping the charging station equipment sanitary. In case of any breakage or accident the chargers may need repairs as well, which might happen intermittently. The warranty prices of manufacturers vary with the type of protection, the particular charging station operator has subscribed for. As applicable to other machinery, the minor repairs might be minimal but repairing an entirely broken charger after the expiration of warranty, might be costly. Hence a strict structure in terms of the responsibility of site host, charging network and installation manager has to be organized before the charging station goes operational. It is estimated that the annual maintenance cost over charging station is around 400 USD per charger per year [90]. Most of the networks like Tesla, ChargePoint, Wallbox, offer a maintenance plan for an additional 
annual fee. There is free online supercharger support contact provided by Tesla for its entire supercharger network.

Apart from the maintenance costs the pricing structure has important role to play in the maintenance scenario. The common pricing structures used in the United States are by $\mathrm{kWh}$, by session, by length of time, or through a subscription. The most used structures are session and time based. It is illegal in the United States to sell electricity other than a utility company. Although $50 \%$ of public charging is free to use the pricing models across different charging network providers vary depending on different issues, such as, members vs. nonmembers, pricing according to subscription, host specifics pricing, and pricing on the kilowatt rate of charge.

As mentioned in Section 11, the collection and analysis of charging infrastructure utilization data contributes to a successful charging station management.

An online portal for utilization data is provided by most charging networks. Sometimes third-party analytics software or a separate electric meter are installed by a nonnetwork charging infrastructure to capture utilization data. Utilization data has a serious risk of breach due to the poor cybersecurity measures implemented by the power grid. If handled carefully, utilization data is very useful to track progress towards emissions and energy goals as well as to determine if a certain pricing structure is successful and to evaluate the need for additional charging infrastructure in the area. A successful maintenance strategy for the long-term operation of charging stations is crucial in order to increase EV's customer base.

\section{Discussion}

Early history of electrical grid saw a battle over AC and DC in which, despite Thomas Edison's best efforts, AC won. AC had the ease of changing voltage levels with transformers and the transmission of electricity seemed easier. But after almost hundred and fifty years later AC power is still predominantly used in grid despite having huge power losses and higher cost.

DC power is energy efficient, reliable, and has a better quality of power. The power density of DC machines is way higher than AC machines. DC also is inherently compatible with free fuel energy (solar and wind) systems generating intermittent DC power stored in batteries to have a reliable power supply. Solar PV is inherently a DC energy supply, as are batteries, making DC a more naturally compatible interface. Any energy storage technology is DC based, creating opportunities for improved integration efficiencies, and reduced operating losses.

Most of the modern electronic equipment like cell phones, laptops, and household appliances are DC. If the requirement for converting energy could be eliminated, then efficiency will increase. Reduced loss will also reduce the dissipated heat in electronic circuitry so that the electronic equipment lasts longer. The technology of DC power in data centers, homes, and communities is making significant advances.

Moreover, different countries operate in different power frequencies and qualities. Due to this, different countries need different conversion equipment which is an additional hassle. If universal DC is accepted, then one single equipment can travel the world. In places like Alaska where human population is scarce, power is generated in a nano grid system and DC is prevalent as it is convenient. In the rural areas of low GDP countries or the war ridden countries which have their power grid destroyed, DC is used. While charging from AC power, whether be it from household $120 \mathrm{~V}$ or $240 \mathrm{~V}$ outlet or use J1772 charging equipment, the car's rectifier converts that power to DC. Therefore, there are multiple levels of conversion and associated losses before the power can reach the battery.

From safety and carbon emission point of view, PV generation of electric power is the best technology [91]. The cost of photovoltaics generated electric power is lower than any other energy source [92]. At utility scale, the cost of PV generated electric power has reached as low as $0.0104 \mathrm{USD} / \mathrm{kWh}$ [92]. Due to advancement in technology and volume manufacturing, the cost of lithium ion batteries is falling constantly [93]. For four hours of 
power storage currently the cost of stored electric power is 0.8 cents $/ \mathrm{kWh}$ to 1.4 cents $/ \mathrm{kWh}$ and has the potential to reach to 0.4 cents $/ \mathrm{kWh}$ to 0.9 cents $/ \mathrm{kWh}$ by 2022 [94]. For longer hours of battery use the cost is significantly reduced. For a standalone photovoltaics and lithium-ion battery power network, ad stowing PV generated power in batteries for 16-18 h, the cost of electric power is roughly half than the cost current AC grid [94].

As mentioned in the introduction, reference [8] has an extensive review of power electronics topologies but other aspects remain untouched. Every aspect of the shortcomings in engineering for charging station has been thoroughly analyzed in this paper. The authors of reference [8] don't delve into the subject of DC grid or silicon carbide power electronics for fast charging. This paper addresses that as well. In reference [9] emphasis is placed on the charging equipment and inductive charging. The scopes of inductive charging remain doubtful economically for heavy duty vehicles because of their high losses. Therefore, this paper recommends the reduction of losses in power systems by adopting $\mathrm{SiC}$ power electronics. In reference [10], the authors discuss all levels of charging, but no special emphasis is given on fast charging, so this paper focuses solely on the XFC architecture. The charging standards are mentioned in [11] but technical aspects are not as deeply investigated as this paper. The energy storage design for DCFC is mentioned in [12] but the important aspects of power electronics, security which are valuable for a good energy storage are not paid attention to, this paper addresses those issues. The emphasis of this review paper is on relevant power electronics technologies of DC fast charging and other aspects such as cyber security, protection, impact of DC power clean electrical power networks and the role of silicon carbide power electronics in fast deployment of XFC on a large-scale basis.

To advance the technology of XFC, advancements must be made both in the power network as well as the XFC. Figure 13 shows our proposed system. If the DC power generated by PV and battery-based power network can be used locally, there is no need of transmission of power. This concept is exactly what Thomas Edison proposed and involve minimum distance between power source and load as well as minimum power conversions [95]. In case of long-haul transmission, HVDC is used and there is opportunity to design and fabricate high voltage solid state silicon carbide converters. The use of larger silicon carbide wafers and the use of single wafer manufacturing has the potential of bringing cost of $\mathrm{SiC}$ power electronics at par or lower than silicon power electronics [95]. Based on the isolation techniques it is far more viable to isolate a DC charging station in case of a cyber-attack. Judging by all these advantages of DC over AC, it is safe to presume that extremely fast charging technology will be far more efficient and cheaper if DC grid was adopted.

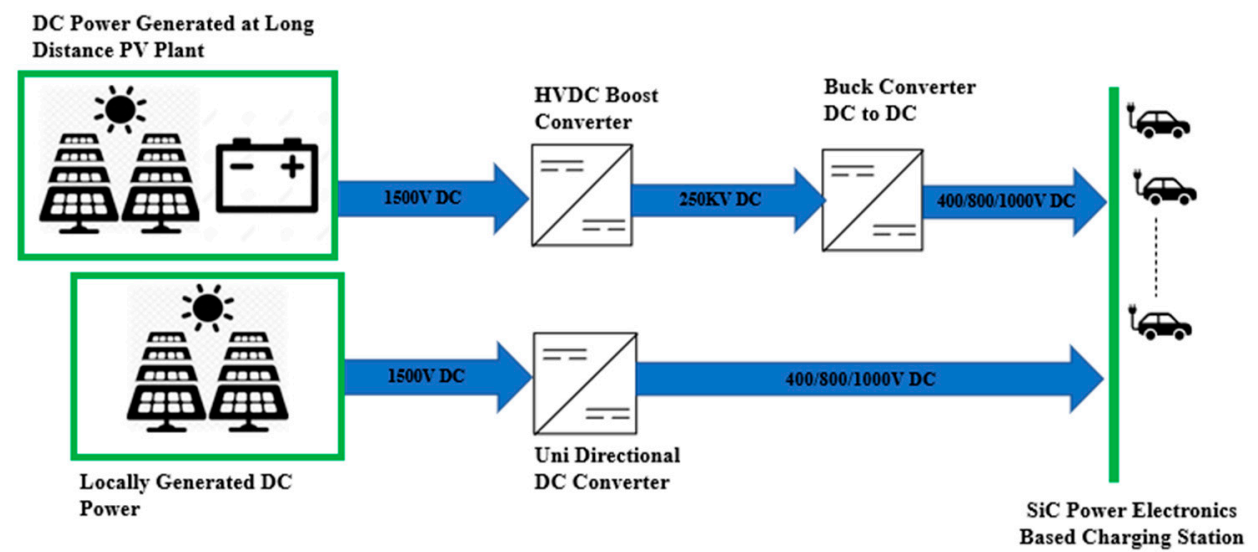

Figure 13. Fully Renewable and DC XFC Charging Infrastructure [14].

\section{Conclusions}

Thorough research and planning are required to make a charging infrastructure that will encourage the consumers to opt for EVs for not only daily usage but also for long 
distance travel and totally forego the ICEV. The power electronics topologies are the cornerstone for charging stations and improving on the current topologies discussed here will make charging stations less expensive, thus more acceptable. The effect of Silicon Carbide in performance improvement of power electronics is discussed. How it effects the environment and what are the cyber threat in the station are also discussed. In this article we have addressed the gaps in research which are hindering the widespread usage of EV in today's scenario. The technology gaps range from power electronics, protection, DC vs. AC to cyber security. Implementing the suggestions proposed here will help reduce power electronics losses, make the protection architecture stronger and secure the network apart from many other aspects. Use of DC power network over AC power can cut down the capital cost of the entire system and provide low-cost charging solution to customers. The acceptance of electric vehicles is not only the individual's responsibility, but it is a responsibility that lies on government and big corporations alike. This article helps the academia by directing the research initiatives and the industry to develop the necessary architecture to implement the XFC. Modeling a free fuel based fully DC network powered by SiC electronics will form the nucleus of the next step of this research. Although we have emphasized the advantages of DC input power for various loads, practical implementation of DC power as input for XFC as well as for other applications depends on the energy policy of individual country.

Author Contributions: Conceptualization: N.D. and R.S. Power Electronics, Protection and SiC implementations: N.D. and R.S., Power Electronics Revision: K.B., Cyber Security: R.R.B., Writing: N.D., review and editing: R.S.; supervision, R.S.; project administration, R.S. All authors have read and agreed to the published version of the manuscript.

Funding: This research received no external funding.

Institutional Review Board Statement: This research was reviewed by the authors.

Informed Consent Statement: All authors have given informed consent to publish this work.

Data Availability Statement: This review paper processed data from reputed journals and cited those.

Conflicts of Interest: The authors declare no conflict of interest.

\section{Nomenclature}

$\begin{array}{ll}\text { AC } & \text { Alternating Current } \\ \text { BMS } & \text { Battery Management System } \\ \text { CPS } & \text { Cyber Physical System } \\ \text { CHAdeMO } & \text { Charge de move } \\ \text { CCS } & \text { Combined Charging System } \\ \text { CAN } & \text { Controller Area Network } \\ \text { DC } & \text { Direct Current } \\ \text { DAB } & \text { Dual Active Bridge } \\ \text { EV } & \text { Electric Vehicle } \\ \text { ESU } & \text { Energy Storage Unit } \\ \text { XFC } & \text { Extremely fast charging station } \\ \text { ICEV } & \text { Internal combustion Engine Vehicle } \\ \text { ECU } & \text { Electronic Control Unit } \\ \text { EPA } & \text { Environmental Protection Agency } \\ \text { EOT } & \text { Electrification of Transportation } \\ \text { EVCS } & \text { Electric Vehicle Charging Station } \\ \text { ESR } & \text { Electrical Service Requirement } \\ \text { IGBT } & \text { Insulated Gate Bipolar Transistor } \\ \text { kW } & \text { Kilowatt } \\ \text { HVDC } & \text { High Voltage Direct Current } \\ \text { MW } & \text { Megawatt }\end{array}$




$\begin{array}{ll}\text { MVAC } & \text { Medium Voltage Alternating current } \\ \text { MOSFET } & \text { Metal oxide semiconductor field effect transistor } \\ \text { PV } & \text { Photovoltaic } \\ \text { PWM } & \text { Pulse Width Modulation } \\ \text { RES } & \text { Renewable Energy System } \\ \text { SoC } & \text { state of charge } \\ \text { SiC } & \text { Silicon Carbide } \\ \text { THD } & \text { Total harmonic distortion } \\ \text { V2G } & \text { Vehicle to Grid }\end{array}$

\section{References}

1. Sources of Greenhouse Gas Emissions. Available online: https://www.epa.gov/ghgemissions/sources-greenhouse-gasemissions (accessed on 1 November 2021).

2. Electric-Vehicle Sales Growth Outpaces Broader Auto Industry. Available online: https://www.wsj.com/articles/electricvehicle-sales-growth-outpaces-broader-auto-industry-11627032601?mod=hp_lead_pos3\&mod=article_inline (accessed on 11 October 2021).

3. Electric Airplanes Are Getting Tantalizingly Close to a Commercial Breakthrough. Available online: https://qz.com/1943592/ electric-airplanes-are-getting-close-to-a-commercial-breakthrough/ (accessed on 11 October 2021).

4. Tesla Working on \$25,000 Hatch, Report Says. Available online: https://www.autoweek.com/news/green-cars/a36876395/teslaworking-on-dollar25000-hatch-report-says / (accessed on 11 October 2021).

5. Understanding U.S. and European Standards for Electric-Vehicle Charging. Available online: https://www.electronicdesign. com/power-management/article/21751240/understanding-us-and-european-standards-for-electricvehicle-charging (accessed on 11 October 2021).

6. Charging Infrastructure Procurement and Installation. Available online: https://afdc.energy.gov/fuels/electricity_infrastructure_ development.html (accessed on 11 October 2021).

7. Lessons Learned on Early Electric Vehicle Fast-Charging Deployments. Available online: https://theicct.org/sites/default/files/ publications/ZEV_fast_charging_white_paper_final.pdf (accessed on 11 October 2021).

8. Tu, H.; Feng, H.; Srdic, S.; Lukic, S. Extreme fast charging of electric vehicles: A technology overview. IEEE Trans. Transp. Electrif. 2019, 5, 861-878. [CrossRef]

9. Dericioglu, C.; Yirik, E.; Unal, E.; Cuma, M.U.; Onur, B.; Tumay, M. A review of charging technologies for commercial electric vehicles. Int. J. Adv. Automot. Technol. 2018, 2, 61-70.

10. Shareef, H.; Islam, M.M.; Mohamed, A. A review of the stage-of-the-art charging technologies, placement methodologies, and impacts of electric vehicles. Renew. Sustain. Energy Rev. 2016, 64, 403-420. [CrossRef]

11. Das, H.S.; Rahman, M.M.; Li, S.; Tan, C.W. Electric vehicles standards, charging infrastructure, and impact on grid integration: A technological review. Renew. Sustain. Energy Rev. 2020, 120, 109618. [CrossRef]

12. Rafi, M.A.H.; Bauman, J. A Comprehensive Review of DC Fast-Charging Stations with Energy Storage: Architectures, Power Converters, and Analysis. IEEE Trans. Transp. Electrif. 2020, 7, 345-368. [CrossRef]

13. Tesla Increases Power Capacity of Superchargers in Europe. Available online: https:/ / electrek.co/2019/08/29/tesla-increasespower-superchargers-europe/ (accessed on 11 October 2021).

14. Deb, N.; Singh, R.; Bai, H. Transformative Role of Silicon Carbide Power Electronics in Providing Low-cost Extremely Fast Charging of Electric Vehicles. In Proceedings of the 2021 IEEE Fourth International Conference on DC Micro Grids (ICDCM), Arlington, VA, USA, 18-21 July 2021; pp. 1-6. [CrossRef]

15. Paniyil, P.; Singh, R.; Powar, V.; Deb, N.; Zhang, J.; Bai, K.; Dubey, A. Batteries and Free Fuel based Photovoltaics and Complimentary Wind Energy based DC Power Networks as 100\% Source of Electric Power around the Globe. In Proceedings of the 2021 IEEE 48th Photovoltaic Specialists Conference (PVSC), Fort Lauderdale, FL, USA, 20-25 June 2021; pp. 1821-1828.

16. Yang, S.N.; Cheng, W.S.; Hsu, Y.C.; Gan, C.H.; Lin, Y.B. Charge scheduling of electric vehicles in highways. Math. Comput. Model. 2013, 57, 2873-2882. [CrossRef]

17. Morrissey, P.; Weldon, P.; O'Mahony, M. Future standard and fast charging infrastructure planning: An analysis of electric vehicle charging behaviour. Energy Policy 2016, 89, 257-270. [CrossRef]

18. Morrow, K.; Karner, D.; Francfort, J.E. Plug-in Hybrid Electric Vehicle Charging Infrastructure Review; CTCN: Copenhagen, Denmark, 2008.

19. Hardman, S.; Jenn, A.; Tal, G.; Axsen, J.; Beard, G.; Daina, N.; Figenbaum, E.; Jakobsson, N.; Jochem, P.; Kinnear, N.; et al. A review of consumer preferences of and interactions with electric vehicle charging infrastructure. Transp. Res. Part D Transp. Environ. 2018, 62, 508-523. [CrossRef]

20. How Will the Grid Adjust to EV Charging? Available online: https://www.tdworld.com/electrification/article/21168252/howwill-the-grid-adjust-to-ev-charging (accessed on 1 November 2021).

21. Leite, R.S.; Afonso, J.L.; Monteiro, V. A novel multilevel bidirectional topology for on-board EV battery chargers in smart grids. Energies 2018, 11, 3453. [CrossRef] 
22. Zhang, Z.; Xu, H.; Shi, L.; Li, D.; Han, Y. A unit power factor DC fast charger for electric vehicle charging station. In Proceedings of the 7th International Power Electronics and Motion Control Conference, Harbin, China, 2-5 June 2012; Volume 1, pp. $411-415$.

23. Zhang, Z.; Xu, H.; Shi, L.; Li, D.; Han, Y. Application research of an electric vehicle DC fast charger in smart grids. In Proceedings of the 2012 IEEE 6th International Conference on Information and Automation for Sustainability, Beijing, China, 27-29 September 2012; pp. 258-261.

24. Du, Y.; Lukic, S.; Jacobson, B.; Huang, A. Review of high power isolated bi-directional DC-DC converters for PHEV/EV DC charging infrastructure. In Proceedings of the 2011 IEEE Energy Conversion Congress and Exposition, Phoenix, AZ, USA, 17-22 September 2011; pp. 553-560.

25. He, P.; Khaligh, A. Comprehensive analyses and comparison of $1 \mathrm{~kW}$ isolated DC-DC converters for bidirectional EV charging systems. IEEE Trans. Transp. Electrif. 2016, 3, 147-156. [CrossRef]

26. Du, Y.; Zhou, X.; Bai, S.; Lukic, S.; Huang, A. Review of non-isolated bi-directional DC-DC converters for plug-in hybrid electric vehicle charge station application at municipal parking decks. In Proceedings of the 2010 Twenty-Fifth Annual IEEE Applied Power Electronics Conference and Exposition (APEC), Palm Springs, CA, USA, 21-25 February 2010; pp. $1145-1151$.

27. Tank, S.B.; Manavar, K.; Adroja, N. Non-isolated bi-directional DC-DC converters for plug-in hybrid electric vehicle charge station application. In Proceedings of the Emerging Trends in Computer \& Electrical Engineering (ETCEE 2015), Rajkot, India, 13-14 March 2015.

28. Kang, T.; Kim, C.; Suh, Y.; Park, H.; Kang, B.; Kim, D. A design and control of bi-directional non-isolated DC-DC converter for rapid electric vehicle charging system. In Proceedings of the 2012 Twenty-Seventh Annual IEEE Applied Power Electronics Conference and Exposition (APEC), Orlando, FL, USA, 5-9 February 2012; pp. 14-21.

29. Shi, L.; Xu, H.; Li, D.; Yuan, Z. A novel high power factor PWM rectifier inverter for electric vehicle charging station. In Proceedings of the 2011 International Conference on Electrical Machines and Systems, Beijing, China, 20-23 August 2011; pp. 1-6.

30. Schupbach, R.M.; Balda, J.C. Comparing DC-DC converters for power management in hybrid electric vehicles. In Proceedings of the IEEE International Electric Machines and Drives Conference, IEMDC'03, Madison, WI, USA, 1-4 June 2003; Volume 3, pp. 1369-1374.

31. Lee, J.Y.; Jeong, Y.S.; Han, B.M. An isolated dc/dc converter using high-frequency unregulated $L L C$ resonant converter for fuel cell applications. IEEE Trans. Ind. Electron. 2010, 58, 2926-2934. [CrossRef]

32. Musavi, F.; Craciun, M.; Gautam, D.S.; Eberle, W.; Dunford, W.G. An LLC resonant DC-DC converter for wide output voltage range battery charging applications. IEEE Trans. Power Electron. 2013, 28, 5437-5445. [CrossRef]

33. Dao, N.D.; Lee, D.C.; Phan, Q.D. High-efficiency SiC-based isolated three-port DC/DC converters for hybrid charging stations. IEEE Trans. Power Electron. 2020, 35, 10455-10465. [CrossRef]

34. Wang, Y.C.; Wu, Y.C.; Lee, T.L. Design and implementation of a bidirectional isolated dual-active-bridge-based DC/DC converter with dual-phase-shift control for electric vehicle battery. In Proceedings of the 2013 IEEE Energy Conversion Congress and Exposition, Denver, CO, USA, 15-19 September 2013; pp. 5468-5475.

35. Rivera, S.; Wu, B.; Kouro, S.; Yaramasu, V.; Wang, J. Electric vehicle charging station using a neutral point clamped converter with bipolar DC bus. IEEE Trans. Ind. Electron. 2014, 62, 1999-2009. [CrossRef]

36. Rajendran, G.; Vaithilingam, C.A.; Naidu, K.; Oruganti, K.S.P. Energy-efficient converters for electric vehicle charging stations. SN Appl. Sci. 2020, 2, 1-15. [CrossRef]

37. Fathabadi, H. Novel wind powered electric vehicle charging station with vehicle-to-grid (V2G) connection capability. Energy Convers. Manag. 2017, 136, 229-239. [CrossRef]

38. White, C.D.; Zhang, K.M. Using vehicle-to-grid technology for frequency regulation and peak-load reduction. J. Power Sources 2011, 196, 3972-3980. [CrossRef]

39. Xu, Z.; Hu, Z.; Song, Y.; Luo, Z.; Zhan, K.; Wu, J. Coordinated charging strategy for PEVs charging stations. In Proceedings of the 2012 IEEE Power and Energy Society General Meeting, San Diego, CA, USA, 22-26 July 2012; pp. 1-8.

40. Mukherjee, J.C.; Gupta, A. A review of charge scheduling of electric vehicles in smart grid. IEEE Syst. J. 2014, 9, 1541-1553. [CrossRef]

41. Derakhshandeh, S.Y.; Masoum, A.S.; Deilami, S.; Masoum, M.A.; Golshan, M.H. Coordination of generation scheduling with PEVs charging in industrial microgrids. IEEE Trans. Power Syst. 2013, 28, 3451-3461. [CrossRef]

42. Koyanagi, F.; Uriu, Y. A strategy of load leveling by charging and discharging time control of electric vehicles. IEEE Trans. Power Syst. 1998, 13, 1179-1184. [CrossRef]

43. Kesler, M.; Kisacikoglu, M.C.; Tolbert, L.M. Vehicle-to-grid reactive power operation using plug-in electric vehicle bidirectional offboard charger. IEEE Trans. Ind. Electron. 2014, 61, 6778-6784. [CrossRef]

44. Yong, J.Y.; Ramachandaramurthy, V.K.; Tan, K.M.; Mithulananthan, N. Bi-directional electric vehicle fast charging station with novel reactive power compensation for voltage regulation. Int. J. Electr. Power Energy Syst. 2015, 64, 300-310. [CrossRef]

45. Andersson, D.; Carlsson, D. Measurement of ABB s Prototype Fast Charging Station for Electric Vehicles. Master's Thesis, Chalmers University of Technology, Gothenburg, Sweden, 2012.

46. Camurca, L.; Gao, X.; Costa, L.F.; Liserre, M. Design of a medium voltage dc fast charging station with grid voltage regulation and central modular multilevel converter. In Proceedings of the 2018 IEEE Energy Conversion Congress and Exposition (ECCE), Portland, OR, USA, 23-27 September 2018; pp. 2798-2804. 
47. Wang, W.V.; Thirmawithana, D.J.; Riar, B.; Zane, R. A novel integrated boost modular multilevel converter for high power wireless EV charging. In Proceedings of the 2018 IEEE Energy Conversion Congress and Exposition (ECCE), Portland, OR, USA, 23-27 September 2018; pp. 81-88.

48. Rubino, L.; Capasso, C.; Veneri, O. Review on plug-in electric vehicle charging architectures integrated with distributed energy sources for sustainable mobility. Appl. Energy 2017, 207, 438-464. [CrossRef]

49. Nademi, H.; Zadeh, M.; Undeland, T. Interfacing an electric vehicle to the grid with modular conversion unit: A case study of a charging station and its control framework. In Proceedings of the IECON 2018-44th Annual Conference of the IEEE Industrial Electronics Society, Washington, DC, USA, 21-23 October 2018; pp. 5171-5176.

50. Deb, N.; Singh, R. Cost Efficiency Analysis of a Solar Energy Integrated Fast Charging Station. ENergetics, 15 December 2020.

51. Nie, Y.M.; Ghamami, M. A corridor-centric approach to planning electric vehicle charging infrastructure. Transp. Res. Part $B$ Methodol. 2013, 57, 172-190. [CrossRef]

52. Paniyil, P.; Singh, R.; Powar, V.; Venayagamoorthy, G.K. Sustainable Power for Electrification of Transportation. In Proceedings of the 2020 Clemson University Power Systems Conference (PSC), Clemson, SC, USA, 10-13 March 2020; pp. 1-7.

53. Ashique, R.H.; Salam, Z.; Aziz, M.J.B.A.; Bhatti, A.R. Integrated photovoltaic-grid dc fast charging system for electric vehicle: A review of the architecture and control. Renew. Sustain. Energy Rev. 2017, 69, 1243-1257. [CrossRef]

54. Preetham, G.; Shireen, W. Photovoltaic charging station for plug-in hybrid electric vehicles in a smart grid environment. In Proceedings of the 2012 IEEE PES Innovative Smart Grid Technologies (ISGT), Washington, DC, USA, 16-20 January 2012; pp. 1-8.

55. Hu, W.; Su, C.; Chen, Z.; Bak-Jensen, B. Optimal operation of plug-in electric vehicles in power systems with high wind power penetrations. IEEE Trans. Sustain. Energy 2013, 4, 577-585.

56. McLaren, J.; Miller, J.; O'Shaughnessy, E.; Wood, E.; Shapiro, E. Emissions Associated with Electric Vehicle Charging: Impact of Electricity Generation Mix, Charging Infrastructure Availability, and Vehicle Type (No. NREL/TP-6A20-64852); National Renewable Energy Lab. (NREL): Golden, CO, USA, 2016.

57. Dowlatabadi, H.; Krupnick, A.J.; Russell, A. Electric Vehicles and the Environment; U.S. Department of Energy, Office of Scientific and Technical Information: Oak Ridge, TN, USA, 1990.

58. Hawkins, T.R.; Gausen, O.M.; Strømman, A.H. Environmental impacts of hybrid and electric vehicles-A review. Int. J. Life Cycle Assess. 2012, 17, 997-1014. [CrossRef]

59. Paniyil, P.; Powar, V.; Singh, R. Sustainable Intelligent Charging Infrastructure for Electrification of Transportation. Energies 2021, 14, 5258. [CrossRef]

60. Khaimar, A.K.; Shah, P.J. Study of various types of faults in HVDC transmission system. In Proceedings of the 2016 International Conference on Global Trends in Signal Processing, Information Computing and Communication (ICGTSPICC), Jalgaon, India, 22-24 December 2016; pp. 480-484.

61. Naveen, G.; Yip, T.H.T.; Xie, Y. Modeling and protection of electric vehicle charging station. In Proceedings of the 20146 th IEEE Power India International Conference (PIICON), Delhi, India, 5-7 December 2014; pp. 1-6.

62. Candelaria, J.; Park, J.D. VSC-HVDC system protection: A review of current methods. In Proceedings of the 2011 IEEE/PES Power Systems Conference and Exposition, Phoenix, AZ, USA, 20-23 March 2011; pp. 1-7.

63. Rodrigues, R.; Du, Y.; Antoniazzi, A.; Cairoli, P. A review of solid-state circuit breakers. IEEE Trans. Power Electron. 2020, 36 , 364-377. [CrossRef]

64. Karunarathna, J.; Madawala, U.; Baguley, C.; Blaabjerg, F.; Sandelic, M. Reliability Analysis of Fast Electric Vehicle Charging Systems. In Proceedings of the 2021 IEEE 12th Energy Conversion Congress \& Exposition-Asia (ECCE-Asia), Singapore, 24-27 May 2021; pp. 1607-1612.

65. Brooks, R.R.; Sander, S.; Deng, J.; Taiber, J. Automobile security concerns. IEEE Veh. Technol. Mag. 2009, 4, 52-64. [CrossRef]

66. Bedi, G.; Venayagamoorthy, G.K.; Singh, R.; Brooks, R.R.; Wang, K.C. Review of Internet of Things (IoT) in electric power and energy systems. IEEE Internet Things J. 2018, 5, 847-870. [CrossRef]

67. Compromise of Saudi Aramco and RasGas. Available online: https://www.cfr.org/cyber-operations/compromise-saudi-aramcoand-rasgas (accessed on 1 November 2021).

68. Sanger, D.E. The Perfect Weapon: War, Sabotage, and Fear in the Cyber Age; Broadway Books: Portland, OR, USA, 2019.

69. Russia-Linked Group Hacks 200 Businesses with Ransomware. Available online: https://www.bloomberg.com/news/articles/ 2021-07-02/russia-linked-group-hacks-about-200-businesses-with-ransomware (accessed on 1 November 2021).

70. How China Transformed into a Prime Cyber Threat to the U.S. Available online: https://www.nytimes.com/2021/07/19 / technology/china-hacking-us.html (accessed on 1 November 2021).

71. Sandworm Team and the Ukrainian Power Authority Attacks. Available online: https://www.fireeye.com/blog/threat-research/ 2016/01/ukraine-and-sandworm-team.html (accessed on 1 November 2021).

72. Falk, R.; Fries, S. Electric vehicle charging infrastructure security considerations and approaches. In Proceedings of the INTERNET 2012: The Fourth International Conference on Evolving Internet, Venice, Italy, 24-29 June 2012; pp. 58-64.

73. Dierks, T.; Rescorla, E. The Transport Layer Security (TLS) Protocol Version 1.2. [N1]. 2008. Available online: https:// ourworldindata.org/ghg-emissions-by-sector (accessed on 1 November 2021). 
74. Bogosyan, S.; Gokasan, M. Novel Strategies for Security-hardened BMS for Extremely Fast Charging of BEVs. In Proceedings of the 2020 IEEE 23rd International Conference on Intelligent Transportation Systems (ITSC), Rhodes, Greece, 20-23 September 2020; pp. 1-7.

75. Dospinescu, O.; Perca, M. Technological integration for increasing the contextual level of information. An. Stiintifice Ale Univ. Alexandru Ioan Cuza Din Iasi-Stiinte Econ. 2011, 58, 571-581.

76. Nabil, M.; Bima, M.; Alsharif, A.; Johnson, W.; Gunukula, S.; Mahmoud, M.; Abdallah, M. Priority-based and privacy-preserving electric vehicle dynamic charging system with divisible e-payment. In Smart Cities Cybersecurity and Privacy; Elsevier: Amsterdam, The Netherlands, 2019; pp. 165-186.

77. Ito, A.; Ylipää, T.; Gullander, P.; Bokrantz, J.; Centerholt, V.; Skoogh, A. Dealing with resistance to the use of Industry 4.0 technologies in production disturbance management. J. Manuf. Technol. Manag. 2021. [CrossRef]

78. Bogosyan, S.; Akgul, T.; Gokasan, M. MTD Based Novel Scheme for BMS Security against CAN Bus Attacks during BEV Charging. In Proceedings of the 2020 9th Mediterranean Conference on Embedded Computing (MECO), Budva, Montenegro, 8-11 June 2020; pp. 1-7.

79. Schneier, B. Click Here to Kill Everybody: Security and Survival in a Hyper-Connected World; WW Norton \& Company: New York, NY, USA, 2018.

80. Anderson, R. Security Engineering: A Guide to Building Dependable Distributed Systems; John Wiley \& Sons: Hoboken, NJ, USA, 2020.

81. Brooks, R.R.; Deng, J. Lies and the lying liars that tell them: A fair and balanced look at TLS. In Proceedings of the Sixth Annual Workshop on Cyber Security and Information Intelligence Research, Oak Ridge, TN, USA, 21-23 April 2010; pp. 1-3.

82. China Declares All Crypto-Currency Transactions Illegal. Available online: https://www.bbc.com/news/technology-58678907 (accessed on 1 November 2021).

83. Miglani, A.; Kumar, N. Deep learning models for traffic flow prediction in autonomous vehicles: A review, solutions, and challenges. Veh. Commun. 2019, 20, 100184. [CrossRef]

84. Han, O.; Kim, J. Uncertainty analysis on electric power consumption. Comput. Mater. Contin. 2021, 68, 2621-2632. [CrossRef]

85. Mahmood, N.S.; Ajmi, A.A.; Sarip, S.; Jamaludin, K.R.; Kaidi, H.M.; Talib, H.A. Implications COVID-19 on performance and energy management in the production electricity. Comput. Mater. Contin. 2021, 69, 895-911. [CrossRef]

86. Frendo, O.; Graf, J.; Gaertner, N.; Stuckenschmidt, H. Data-driven smart charging for heterogeneous electric vehicle fleets. Energy AI 2020, 1, 100007. [CrossRef]

87. Shahriar, S.; Al-Ali, A.R.; Osman, A.H.; Dhou, S.; Nijim, M. Machine learning approaches for EV charging behavior: A review. IEEE Access 2020, 8, 168980-168993. [CrossRef]

88. Kharlamova, N.; Hashemi, S.; Træholt, C. The Cyber Security of Battery Energy Storage Systems and Adoption of Data-driven Methods. In Proceedings of the 2020 IEEE Third International Conference on Artificial Intelligence and Knowledge Engineering (AIKE), Laguna Hills, CA, USA, 9-13 December 2020; pp. 188-192.

89. Charging Infrastructure Operation and Maintenance. Available online: https://afdc.energy.gov/fuels/electricity_infrastructure_ maintenance_and_operation.html (accessed on 1 November 2021).

90. Why Did Renewables Become So Cheap So Fast? Available online: https://ourworldindata.org/cheap-renewables-growth (accessed on 1 November 2021).

91. Saudi Arabia's Second PV Tender Draws World Record Low Bid of $\$ 0.0104 / \mathrm{kWh}$. Available online: https://www.pv-magazine. com/2021/04/08/saudi-arabias-second-pv-tender-draws-world-record-low-bid-of-0104-kwh/ (accessed on 1 November 2021).

92. Study Reveals Plunge in Lithium-Ion Battery Costs. Available online: https://news.mit.edu/2021/lithium-ion-battery-costs-0323 (accessed on 1 November 2021).

93. This Renewable Energy Juggernaut Wants to Supercharge America's Battery Storage Capacity. Available online: https://www. fool.com/amp/investing/2020/09/05/this-renewable-energy-juggernaut-wants-to-supercha/ (accessed on 1 November 2021).

94. Singh, R.; Shenai, K. DC Microgrids and the Virtues of Local Electricity. IEEE Spectr. 2014, 6. Available online: https://spectrum. ieee.org/dc-microgrids-and-the-virtues-of-local-electricity (accessed on 1 November 2021).

95. Singh, R.; Asif, A.A. Ultra large-scale manufacturing challenges of silicon carbide and gallium nitride based power devices and systems. ECS Trans. 2016, 75, 11. [CrossRef] 